\title{
AN ADVANCED THERMOHYDRAULIC SIMULATION CODE FOR POOL-TYPE LMFBRS (SSC-P CODE)
}

\author{
I.K. MadNI and E.G. CazzoLI
}

Date Published - September 1980

CODE DEVELOPMENT AND VERIFICATION GROUP

DEPARTMENT OF NUCLEAR ENERGY, BROOKHAVEN NATIONAL LABORATORY UPTON, NEW YORK 11973

\footnotetext{
Prepared for the U.S. Nuclear Regulatory Commission

Office of Nuclear Regulatory Research

Washington, D.C. 20555
} 


\section{DISCLAIMER}

This report was prepared as an account of work sponsored by an agency of the United States Government. Neither the United States Government nor any agency Thereof, nor any of their employees, makes any warranty, express or implied, or assumes any legal liability or responsibility for the accuracy, completeness, or usefulness of any information, apparatus, product, or process disclosed, or represents that its use would not infringe privately owned rights. Reference herein to any specific commercial product, process, or service by trade name, trademark, manufacturer, or otherwise does not necessarily constitute or imply its endorsement, recommendation, or favoring by the United States Government or any agency thereof. The views and opinions of authors expressed herein do not necessarily state or reflect those of the United States Government or any agency thereof. 


\section{DISCLAIMER}

Portions of this document may be illegible in electronic image products. Images are produced from the best available original document. 


\title{
AN ADVANCED THERMOHYDRAULIC SIMULATION CODE FOR POOL-TYPE LMFBRS (SSC-P CODE)
}

\begin{abstract}
I.K. MadNI and E.G. Cazzoll
DISCLAIMER

This report was prepared as an account of work sponsored by an agency of the United States Government. " Neither the United States Government nor any agency thereof, nor any of their employees, makes any warranty, express or implied, or assumes any legal liability or responsibility for the accuracy, completeness, or usefulness of any information, apparatus, product, or process disclosed, or represents that its use would not infringe privately owned rights. Reference herein to any specific commercial product, process, or service by trade name, trademark, manufacturer, or otherwise does not necessarily constitute or imply its endorsement, recommendation, or favoring by the United States Government or any agency thereof. The vicws and opinions of authors expressed herein do not necessarily state or reflect those of the United States Government or any agency thereof.
\end{abstract}

\section{Manuscript Completed - August 1980 \\ Date Published - September 1980}

\author{
CODE DEVELOPMENT AND VERIFICATION GROUP \\ DEPARTMENT OF NUCLEAR ENERGY \\ BROOKHAVEN NATIONAL LABORATORY \\ UPTON, NEW YORK 11973
}

Prepared for the

UNITED STATES NUCLEAR REGULATORY COMMISSION OFFICE OF NUCLEAR REGULATORY RESEARCH

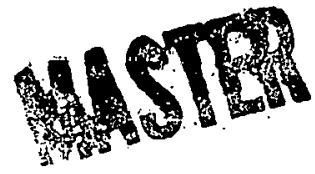

WASHINGTON, D.C. 20555

UNDER CONTRACT NO. DE-AC02-76CH00016

NRC FIN NO. A-3015

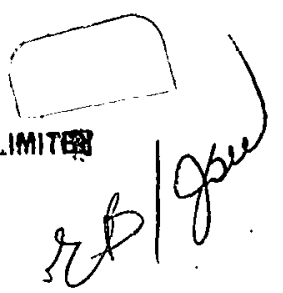




\section{NOTICE}

This report was prepared as an account of work sponsored by an agency of the United States Government. Neither the United States Government nor any agency thereof, or any of their employees, makes any warranty, expressed or implied, or assumes any legal liability or responsibility for any third party's use, or the results of such use, of any information, apparatus, product or process disclosed in this report, or represents that its use by such third party would not'infringe privately owned rights.

The views expressed in this report are not necessarily those of the U.S. Nuclear Regulatory Commission.

Available from GPO Sales Program

Division of Technical Information and Document Control

U.S. Nuclear Regulatory Commission

Washington, D.C. 20555 and

National Technical Information Service Springfield, Virginia 22161 
THIS PAGE

\section{WAS INTENTIONALLY \\ LEFT BLANK}




\section{FOREWORD}

As a part of the Super System Code (SSC) development project for simulating thermohydraulic transients in LMFBRs, the SSC-P code has been developed at Brookhaven National Laboratory. This code is intended to simulate system response to a malfunction anywhere in the heat transport system of a pool-type LMFBR design. This topical report describes the modeling and coding efforts for the SSC-P code. A users' manual is under preparation and will be issued as a separate report.

This work, covered under budget activity No. 60-19-20-01-1, was performed for the Office of the Assistant Director for Advanced Reactor Safety Research, Division of Reactor Safety Research, United States Nuclear Regulatory Commission. 
THIS PAGE

\section{WAS INTENTIONALLY LEFT BLANK}


FOREWORD

i i i

LIST OF FIGURES

viii

LIST OF TABLES

NOMENCLATURE

ACKNOWLEDGMENT

1. ABSTRACT

2. INTRODUCTION

3. STEADY-STATE MODELS

3.1 GLOBAL THERMAL BALANCE

3.2 ENERGY BALANCE IN POOLS

3.2.1 Hot Pool Balance

3.2.2 Cold Pool Balance

3.2.3 Barrier Heat Transfer

3.2.3.1 Areas

3.2.3.2 Film Coefficients

3.3 PRIMARY HYDRAULICS

3.3.1 Intermediate Heat Exchanger: :

3.3.2 Cold Leg Piping

3.3.3 Liquid Levels in Pools

3.3.4 External Bypass

3.3.5 Pressure Drops in Pools

3.3.6 Pumps
21

ix

$x$

$x$ iv

$x i v$

1

9

10

15

17

22

25

27

30

30

34

34

35

36

36 
4. TRANSIENT MODELS

4.1 PRIMARY COOLANT DYNAMICS

4.1.1 Flow Equations

4.1.1.1 Intact System

4.1.1.2 Damaged System

.40

4.1.2 Liquid Levels in Pools

4.1.3 External Bypass

4.1.4 Reactor Inlet Pressure

4.1.4.1 Intact System

4.1.4.2 Damaged System

4.2 INTERMEDIATE SYSTEM

4.2.1 Spherical Pump Tank Model

4.2.1.1 Solution of Cubic Equation

4.3 ENERGY BALANCE IN POOLS

50

4.3.1 Hot Pool Stratification 50

4.3.1.1 Heat Transfer Areas 52

4.3.1.2 Volumes of Zones 54

4.3.1.3 Energy Equations 54

4.4 INTERMEDIATE HEAT EXCHANGER 58

4.4.1 Pressure Losses 59

4.4.2 Heat Transfer 62

4.5 SOLUTION PROCEDURE 65

4.6 SOME CONSIDERATIONS FOR COLD POOL CONCEPT 72

5. INPUT DATA PREPARATION 75

5.1 CORE DATA 75

5.1.1 Flow Fractions 75

5.1.2 Power Fractions 76 
$\begin{array}{lll}5.1 .3 & \text { Fuel Hot Channel } & 77\end{array}$

5.1.4 Axial Power Profile in Fuel 78

$\begin{array}{llr}5.2 & \text { PRIMARY SYSTEM } & 80\end{array}$

$\begin{array}{llr}5.2 .1 & \text { Pump Parameters } & 80\end{array}$

5.2.2 Data on Structures 81

6. CODE DESCRIPTION $\quad 84$

6.1 CODE DEVELOPMENT APPROACH

6.2 FLOW CHARTS AND SUBROUTINE DESCRIPTIONS 86

$\begin{array}{lr}\text { REFERENCES } & 90\end{array}$ 


\section{LIST OF FIGURES}

Figure

1

2
Title

Page

Primary System schematics a) Pool-type LMFBR

b) Loop-type LMFBR

Configuration options in pool-type LMFBR primary system

Schematic diagram of Phenix heat transport circuit

Logic for SSC-P overall steady-state solution

Plant schematic for global balance

Iterative logic for global thermal balance

Primary system configuration for tank energy balance

Driver logic for steady-state energy balance in the sodium pools (hot pool design)

Logic for steady-state thermal balance in hot pool

Solution procedure for thermal balance in cold pool

23

Thermal barrier configuration

Logic to calculate overall barrier heat transfer coefficients

Configuration for calculation of barrier heat transfer area

Hydraulic profile of primary tank and components

Steady-state logic for primary hydraulic calculations

Phenix expansion tank and secondary pump

Model configuration for spherical expansion tank

Configuration for calculation of heat transfer areas fran the two zones to the barrier

Profile of intermediate heat exchanger

Driver for transient thermal-hydraulic calculations in primary system

Calculational logic for primary hydraulics 
Figure

22

23

24

25

26

Calculational logic for energy balance within primary tank

Three main driver programs of SSC-P

70

MAIN9S flow diagram

70

MAIN9T flow diagram

71

DRIV1T flow diagram

71

\section{LIST OF TABLES}

Table

Title

Page

Steady-state power and flow fractions

78 
Symbol

A

C

D

$D_{h}$

e

$f$

$F_{p}$

$F_{X}$

g

Gr

H

$\mathrm{h}$

I

K

k

L

$L, \ell$

$M, m$

$N$

$N_{p}$

$\mathrm{N}_{\mathrm{S}}$

$n_{I}$

$n_{p}$

$n_{t}$

$n_{x}$

$\mathrm{Nu}$

$P$

$P$

$P$

$\hat{P}_{\text {ext }}$
Description

Cross-sectional area or heat transfer area

Specific heat capacity.

Diameter

Hydraulic diameter

Specific enthalpy

Fraction, factor

Number of pumps lumped into a flow path

Number of IHXs lumped into a flow path

Gravitational acceleration

Grashoff number

Pump head

Film heat transfer coefficient

Moment of inertia

Loss coefficient

Thermal conductivity

Length of pipe section

Lengith

Mass

Number of nodes in a pipe run or IHX section

Number of plates in barrier

Specific speed of pump.

Number of intermediate loops

Number of pumps in primary system

Number of active tubes in IHX

Number of IHXs

Nusselt number

Pitch

Pressure

Power

Pressure external to the break $\underline{\text { Unit }}$

$\mathrm{m}^{2}$

$\mathrm{J} / \mathrm{kg}-\mathrm{K}$

m

m

$\mathrm{J} / \mathrm{kg}$

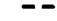

--

$\mathrm{N} / \mathrm{m}^{2}$

m

$w / m^{2}-k$

$\mathrm{kg}-\mathrm{m}^{2}$

--

$W / m-K$

$\mathrm{m}$

m

$\mathrm{kg}$

--

--

--

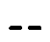

--

--

--

--

$\mathrm{m}$

$\mathrm{N} / \mathrm{m}^{2}$

W

$\mathrm{N} / \mathrm{m}^{2}$ 


\section{NOMENCLATURE (cont)}

Symbol

$\mathrm{Pr}$

$q$

ro

$\mathrm{R}$

$\mathrm{R}_{\mathrm{T}}$

$\mathrm{Ra}$

$\operatorname{Re}$

$\mathrm{T}$

$\mathrm{t}$

U

V

$V_{\ell}$

W

$W_{\text {I }}$

$W_{\text {Ptot }}$

$w_{x \text { tot }}$

$x$

$z$

z

$z_{j}$

$z_{\cdot}$

$\alpha$

B

$\Delta$

$\delta$

$\theta$

$\theta_{\ell}$

$\mu$

v

$\rho$

$\rho_{H}$

${ }^{\rho} \mathrm{C}$

$\tau$

$\Omega$
Description

Prandtl number

Heat transfer rate

Discharge radius of jet

Gas constant

Composite barrier resistance

Rayleigh number (RePr)

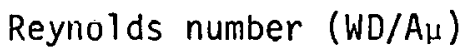

Temperature

Time

Overall heat transfer coefficient

volume

Volume of liquid in spherical pump tank

Mass flow rate

Intermediate loop flow rate

Total flow from all primary pumps

Total flow from all IHXs

Axial coordinate

Vertical coordinate measured from reactor

inlet as reference

Vertical distance

Jet penetration distance

Liquid level in spherical pump tank.

Normalized pump speed $\left(\Omega / \Omega_{R}\right)$

Bypass fraction

Difference or loss

Thickness

Angle made with horizontal

Angle associated with liquid level in spherical tank

Dynamic viscosity

Kinematic viscosity

Coolant density

Density of hot pool sodium

Density of cold pool sodium

Torque

Pump speed
Unit

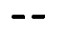

W

$m$

$m^{2}$

$\mathrm{K} / \mathrm{W}$

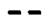

$-$

K

$\mathrm{s}$

$w / m^{2}-k$

$\mathrm{m}^{3}$

$m^{3}$

$\mathrm{kg} / \mathrm{s}$

$\mathrm{kg} / \mathrm{s}$

$\mathrm{kg} / \mathrm{s}$

$\mathrm{kg} / \mathrm{s}$

m

m

$m$

m

m

degrees

degrees

$\mathrm{N}-\mathrm{s} / \mathrm{m}^{2}$

$\mathrm{m}^{2} / \mathrm{s}$

$\mathrm{kg} / \mathrm{m}^{3}$

$\mathrm{kg} / \mathrm{m}^{3}$

$\mathrm{kg} / \mathrm{m}^{3}$

$N-m$

$\mathrm{rad} / \mathrm{s}$ 
NOMENCLATURE (cont)

Subscript

$A, a$

a , amb

acc

$B, b$

b

barr

BP

C

c

$\mathrm{cg}$

$C P, C$

$\mathrm{CW}$

CV

e

$f$

$f$

$f, g$

$\mathrm{g}$

$H P, h$

I

i

in

$\mathrm{m} 1, \mathrm{~m} 2, \mathrm{~m} 3$

m4

$\mathrm{Na}$

0

$p$

$p$

Pin

Po

psh

pt

$\mathrm{R}$
Description

Sodium in zone $A$

Ambient

Acceleration

Sodium in zone $B$

At break location

Barrier value

External bypass flow

Core flow

Contraction

Cold pool to cover gas

Cold pool value

Coolant to wall

Check valve

Expansion

Fuel

Friction

Friction, Gravity, etc.

Cover gas value

Hot pool value

Intermediate

Value at nodal point $i$.

Inlet

Metal in hot pool

Metal in cold pool

Sodium

Outlet

Pump value

Primary

Pump inlet

Pump outlet

Primary to shell wall

Primary to tube wall

Rated value 
NOMENCLATURE (cont)

Subscript

Rin

Ro

S

$\mathrm{S}$

$s$

sh

st

$t$

w

$x$

$x$

$x$ in

$x_{0}$

$1 x$

$2 x$
Description

Reactonr inlet

Reactor outlet

Steam

Secondary

Steel

Shell

Secondary to tube wall

Tube

Wal1

IHX value

Co-ordinate in flow direction

IHX inlet

IHX outlet

Primary side of IHX

Secondary side of IHX 


\section{ABSTRACT}

Models for components and processes that are needed for simulation of thermohydraulic transients in a pool-type liquid metal fast breeder reactor (LMFBR) plant are described in this report. A computer code, SSC-P, has been developed as a part of the Super System Code (SSC) development project.

A users' manual is being prepared as a separate document.

\section{ACKNOWLEDGMENT}

A note of appreciation and thanks is due to A. K. Agrawal, S. F. Carter and M. Khatib-Rahbar for their assistance in the initial phase of this work.

Thanks are also due to R. J. Cerbone and J. G. Guppy for reviewing the report and to $P$. Siemen for her skillful typing of the manuscript.

This work was performed under the auspices of the U.S. Nuclear Regulatory Commission. 


\section{INTRODUCTION}

Based on current liquid metal-cooled fast breeder reactor (LMFBR) technology, a commercial LMFBR power plant could be either of the loop-type or pool-type design. Primary interest in the U.S. has centered on the loop concept, while in Europe and Asia interest has been divided. The French and British have selected the pool concept for their large plants, and the Germans and Japanese have. selected the loop concept, while the Russians are trying one of each. Judging from the successful experiences with pool systems, e.g., EBR-II in the U.S., Phenix in France, and PFR in the United Kingdom, the pool design stands as a viable option to the loop design.

The inherent difference between the pool and loop design options lies in the primary heat transport system. In the former, the entire radioactive primary system including pumps, intermediate heat exchangers (IHXs), reactor and associated piping is enclosed in a large tank filled with sodium. This is in contrast to the latter arrangement, in which all the primary components are connected via piping to form loops attached externally to the reactor vessel. Figure 1 illustrates this difference. The intermediate and tertiary systems of both options are generically identical. Some of the pool-type primary system characteristics and advantages stemming from its integral and enclosed design are delineated below:

(i) All components are submerged in the coolant. This would render the consequences of a pipe rupture accident less severe because of a constant back pressure exerted against the coolant flow nitt. of the break.

(ii) Piping lengths are fairly short. 
(iii) There is a large inventory of sodium

(iv) Pumps as a rule are located in the cold leg of the heat transport circuit.

(v) Due to the large volume of the cold pool, the reactor inlet plenum is not important.

(vi) The check valve is usually included in the removable pump unit.

(vii) There is only one cover gas space. This eliminates the need for separate cover gas systems over liquid levels in pumps and IHX.

(viii) Due to the large thermal inertia of the pool, emergency cooling of the pool is totally decoupled from the emergency cooling requirements of the core which simplifies the design. However, this implies that this very large thermal inertia may keep the pool cool, even though the core sodium is boiling away. Therefore, natural convection is just as important as in loop-type primary systems.

There are some disadvantages stemming from problems of accessibility for inspection and maintenance, thermal expansion effects, and plant lifetime insulation requirements.

There are currently lwo key altcrnative primary system concepts for pool designs based on the choice of reactor outlet plenum; these are namely, the hot pool concept and the cold pool concept which are illustrated in Fig. 2 . Only important components have been shown. In both coricepts, the pump draws sodium from an open pool and supplies core flow.

In the hot pool concept, there is no pipe connection between the reactor outlet and the IHX inlet. The coolant exiting the core enters an open pool; during steady state operation, this open pool temperature is at approximately the reactor mixed mean outlet temperature. The sodium in this hot pool is 


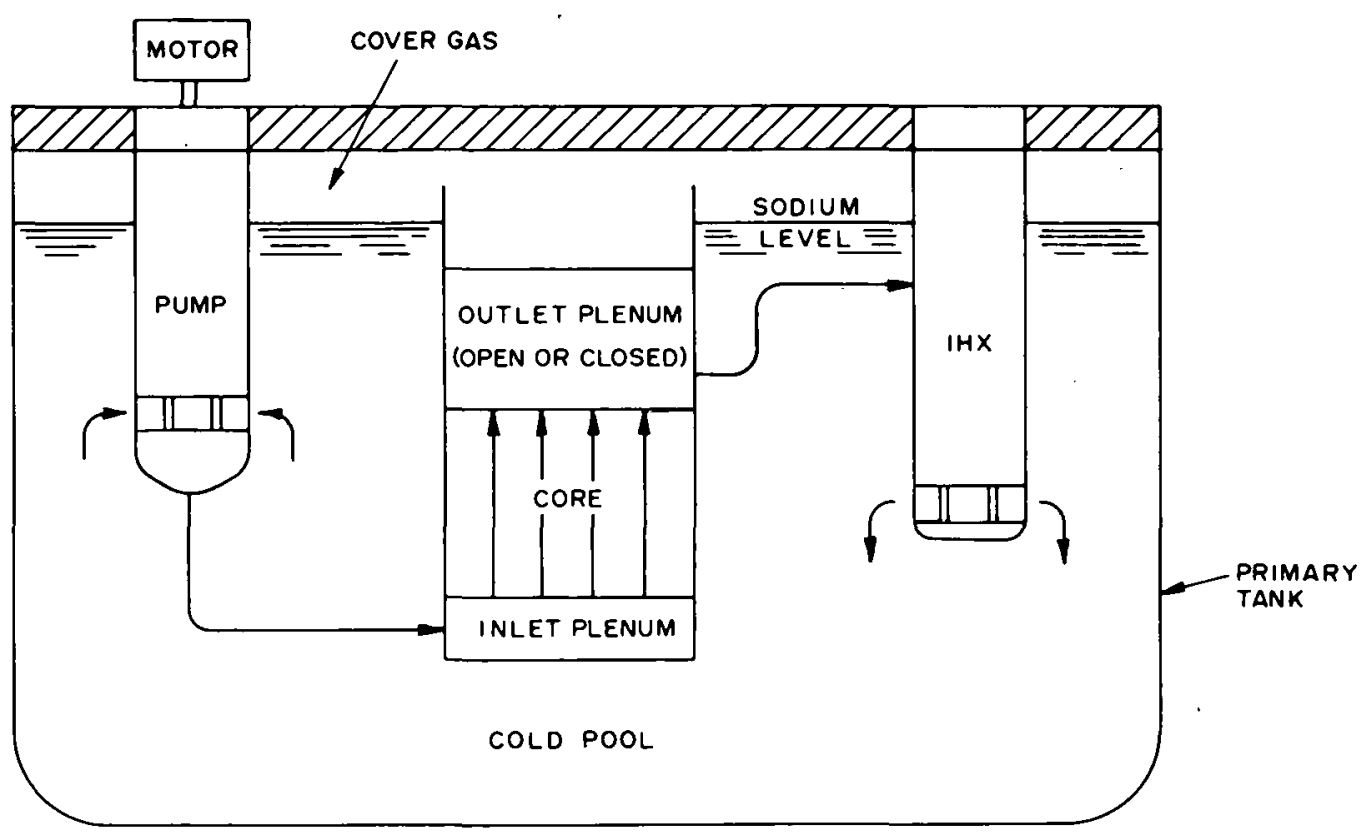

(a) Pool-type LMFBR

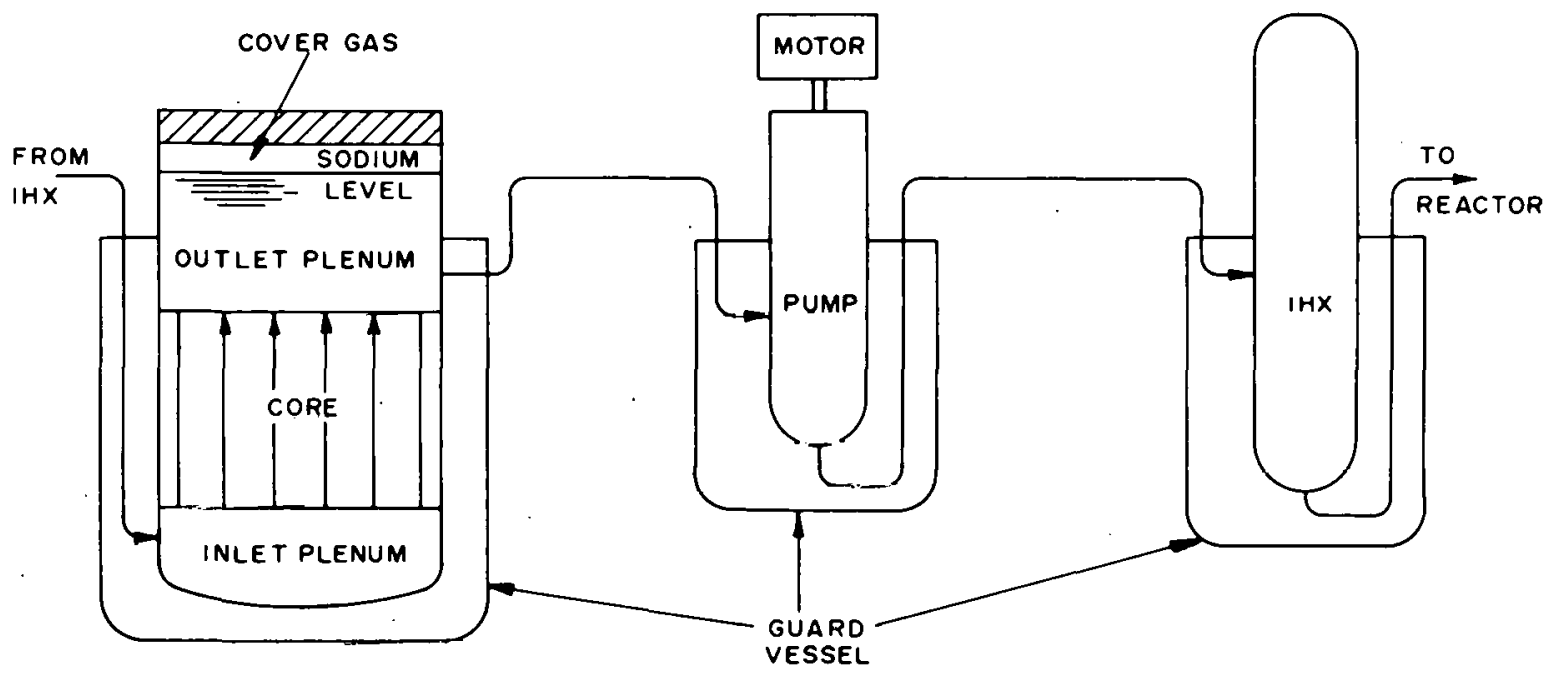

(b) Loop-type LMFBR

Figure 1. Primary System schematics 


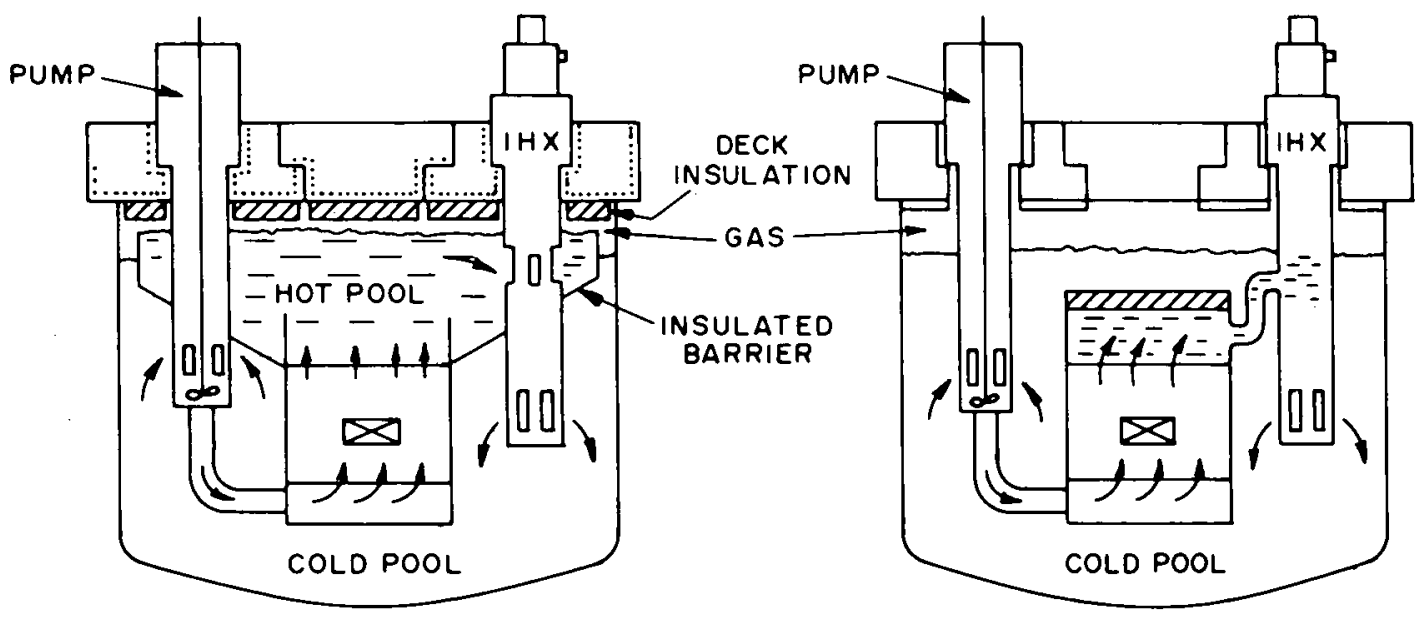

(a) Hot Pool Concept

(b) Cold Pool Concept

Figure 2. Configuration options in pool-type LMFBR primary system 
- separated from the cooler sodium in the pump suction region of the tank by an insulating barrier. In general, the liquid levels in the hot and cold pools, are different; this level difference accounts for the hydraulic losses and gravitational heads occurring during flow through the IHX. These levels will vary with changes in the total coolant flow through the IHXs and flow through the core.

The cold pool concept utilizes an enclosed reactor outlet plenum, similar to that in the loop design except for the absence of cover gas. Hot sodium leaves the outlet plenum and flows to the IHX via a short length of insulated piping. The bulk sodium of the pool is at the reactor inlet temperature and only one liquid level exists. In either concept, the pump outlet is connected via piping to the reactor inlet. The IHX outlet to the pump inlet is in the cold pool environment. In both concepts, an elevated IHX arrangement is used to promote natural convection in the absence of forced cooling.

As mentioned earlier, the insulated barrier (hot pool concept) and the hot leg piping (cold pool concept) have to operate in a sodium environment for the life of the plant.

The hot pool concept has been implemented in operating prototype plants, namely, Phenix (France), PFR (United Kingdom), it will also be implemented in the Superphenix (France) and CFR (United Kingdom) commercial plants. In contrast, the cold pool concept has unly been implemented in the experimental, albeit successful EBR-II plant (U.S.A.). Furthermore, all U.S. EPRI-sponsored pool-type prototype large breeder reactor (PLBR) design studies have been based on the hot pool concept.

Restricted analytical models and associated computer codes such as MELANI, NATDEMO ${ }^{2}$, and UEMO-POOL ${ }^{3}$ have been develuped by other organizations to simu- 
late the overall response for specific plants. The first code, MELANI, was " designed for the Prototype Fast Reactor (PFR). NATDEMO models the EBR-II plant, and is a combination of $\operatorname{NATCON}^{4}$ describing the primary system and DEMO, an adaptation of the original DEMO $\operatorname{code}^{5}$ to model the secondary and tertiary systems. DEMO-POOL is an adaptation of the DEMO code ${ }^{5}$ to model the conceptual pool-type PLBR design study by the General Electric Company. More recently, an extension of the fast-running CURL code ${ }^{6}$ to model pool-type plants has been reported ${ }^{7}$.

Since an LMFBR plant using the pool concept is a viable option for the U.S., a general system code is required by NRC for the safety analysis of pool-type LMFBRs. A program was therefore initiated at $B N L^{8}$ to develop an advanced thermohydraulic system transient code for pool-type LMFBR plants, capable of predicting plant response under various off-normal and accident conditions. This code is designed to analyze the system response to a malfunction anywhere in the heat transport system of the plant. In all events, computations are terminated when loss of core integrity is indicated (i.e., when clad temperature reaches its melting point).

Another key teature of like code is the sapahility of performing steadystate or preaccident initialization. The initialized conditions are calculated from user-specified design parameters and operating conditions. A restart capability is provided so that a series of transient analyses can be made from a single steady-state computation; a restart option during transient analyses is also available.

Although emphasis of the code development was on transient analyses required for safety, this code can be utilized for other purposes such as (a) design scoping analyses and (b) specification of various components. 
The models developed for the SSC-P code are reported. The essential components and their arrangement in a pool system, such as the Phenix reactor plant, are schematically shown in Fig. 3. Under normal operation, liquid sodium flows in the primary and intermediate (secondary) systems as indicated by the direction of the arrows. Although only one circuit is explicitly shown in the figure, a plant does have more than one circuit. There can be more than one pump feeding sodium into the core, and more than one IHX transferring heat to the secondary system. In general, the number of pumps and IHXs are not required to be the same and are specified as input parameters in the SSC-P code. The number of secondary loops in the plant is determined by the number of IHXs serving each loop.

A comprehensive description of the models is given in Sections 3 and 4; the steady-state plant characterization, prior to the initiation of transients is described in Chapter 3 and their transient counterparts are discussed-in Section 4. The analytical effort thus far has been guided largely by the Phenix design; the Phenix input data deck has evolved from an extensive search of the available literature. In Section 5 a discussion is presented on the ways in which some of the data, which were not directly available in the literature, were obtained.

Section 6 presents a summary of the development approach used for SSC-P. Since many portinns of SSC.P utili<e the same methods and models as its parcnt code $\mathrm{SSC}-\mathrm{L},{ }^{9}$ the primary emphasis in the development and its description in this report has been to focus on the differences between the two codes. In particular, it is our purpose to highlight the new models and modifications required for pool type LMFBR simulation. 


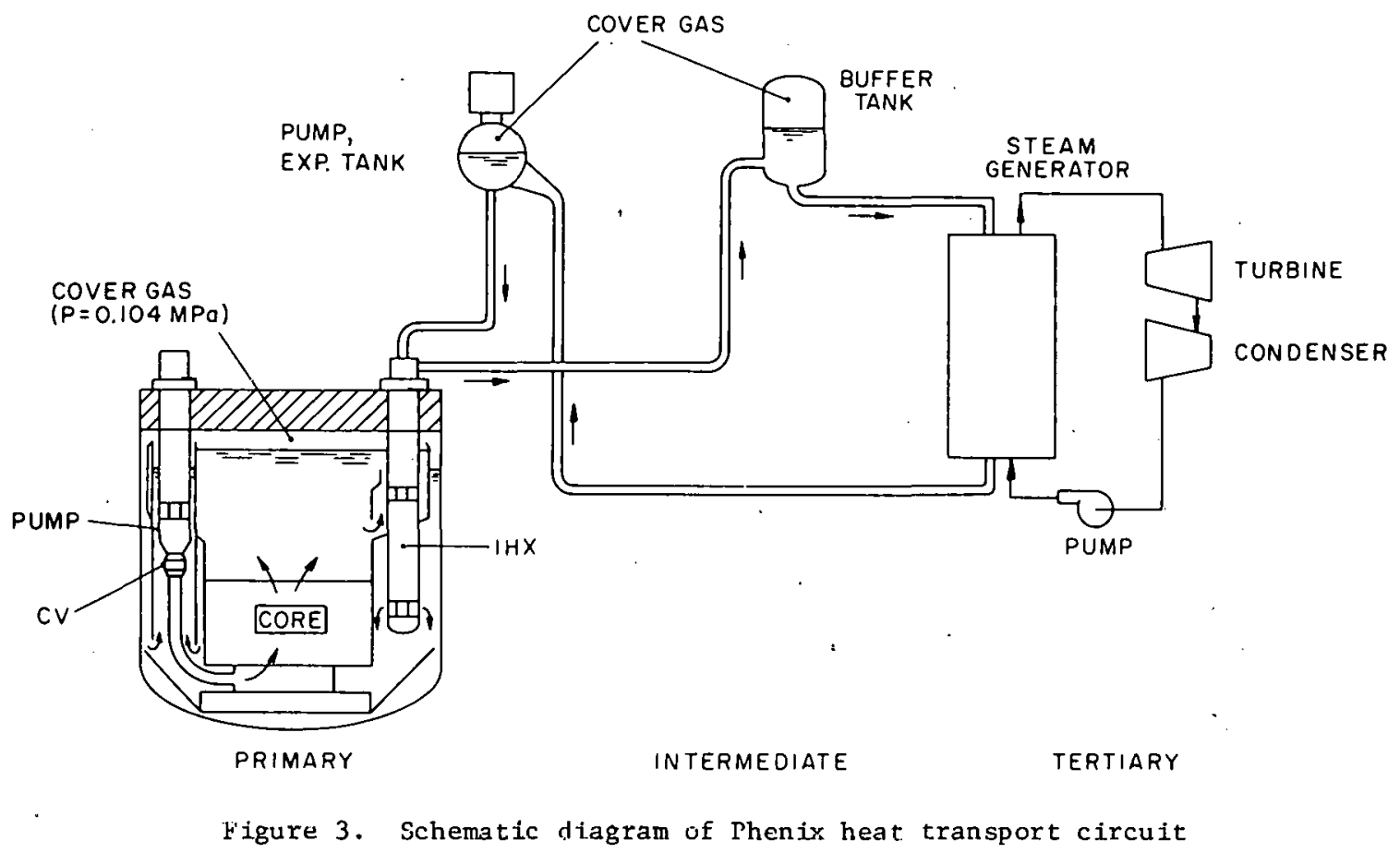

Figure 3. Schematic diagram of Phenix heat transport circuit 


\section{STEADY-STATE MODELS}

As shown in Fig. 3, the primary heat transport system of a pool-type LMFBR plant is one in which consists of all of the essential components are located within the primary tank. This includes reactor, pumps, check valves, primary side of the intermediate heat exchangers, sodium pools, cover gas blanket, and piping. Excluded is the secondary side of the IHX, which is considered part of the secondary system. The centrifugal pump is a variable speed pump. It provides the driving head to offset the pressure losses opposing coolant flow. There is no separate pump tank with its own cover gas volume. The absolute pressure is the primary system is determined by the specification of the cover gas blanket pressure. Typically, the cover gas pressure is very close to atmospheric pressure.

The intermediate heat transport system is similar to that used in the loop-type designs. It includes the secondary side of the IHX, the sodium side of the stean generator, the buffer (surge) tank to accommodate changes in sodium volume, a pump with its own tank and cover gas volume, and the piping connecting all these components. The steam generator constitutes the essential part of the tertiary or water/steam circuit. The modeling for the intermediate and tertiary circuits has essentially been carried over from the SSC-L code.

In the initial part of the transient calculation, a stable and unique steady-state or pretransient solution for the entire plant must be obtained, starting from user-specified design parameters and operating conditions. As a result, the continuity, energy, and momentum conservation equations in timeindependent form are reduced, to a set of nonlinear algebraic equations. These 
equations are solved in two steps. First, the global parameters are obtained. More detailed characterization is achieved by using the global conditions obtained in the first step, as boundary conditions. Figure 4 is a schematic illustration of the overall SSC-P steady-state solution procedure. Details of the global thermal balance, primary system thermal-hydraulics, and individual component models, are discussed in the following subsections.

\subsection{GLOBAL THERMAL BALANCE}

Calculations required for global thermal balance are not significantly different from those used in SSC-L calculations. The main differences arise from the absence of direct piping connections between the IHXs and the reactor in the hot pool concept. In addition, the logic is slightly altered to allow for more than one IHX per intermediate loop in the pool system. For clarity of presentation, the entire global balance as implemented in SSC-P will be described here, instead of just the differences from SSC-L.

A schematic diagram of the heat transport circuit for thermal balance is shown in Fig. 5. The reactor is missing in the figure, the reasons for which will become clear later. Gross energy balance may be represented by the following five independent equations:

$$
\begin{aligned}
& P_{X}=W_{T X}\left[e\left(T_{X i n}\right)-e\left(T_{X_{0}}\right)\right] \\
& P_{X}=U_{X} A_{X} \Delta T_{X} L_{M} \\
& P=W_{I}\left[e\left(T_{I 0}\right)-e\left(T_{I i n}\right)\right] \\
& P=U_{S G} A_{S G} \Delta T_{S G}{ }^{L M} \\
& P=W_{S}\left[e_{S O}-e_{F W}\right]
\end{aligned}
$$




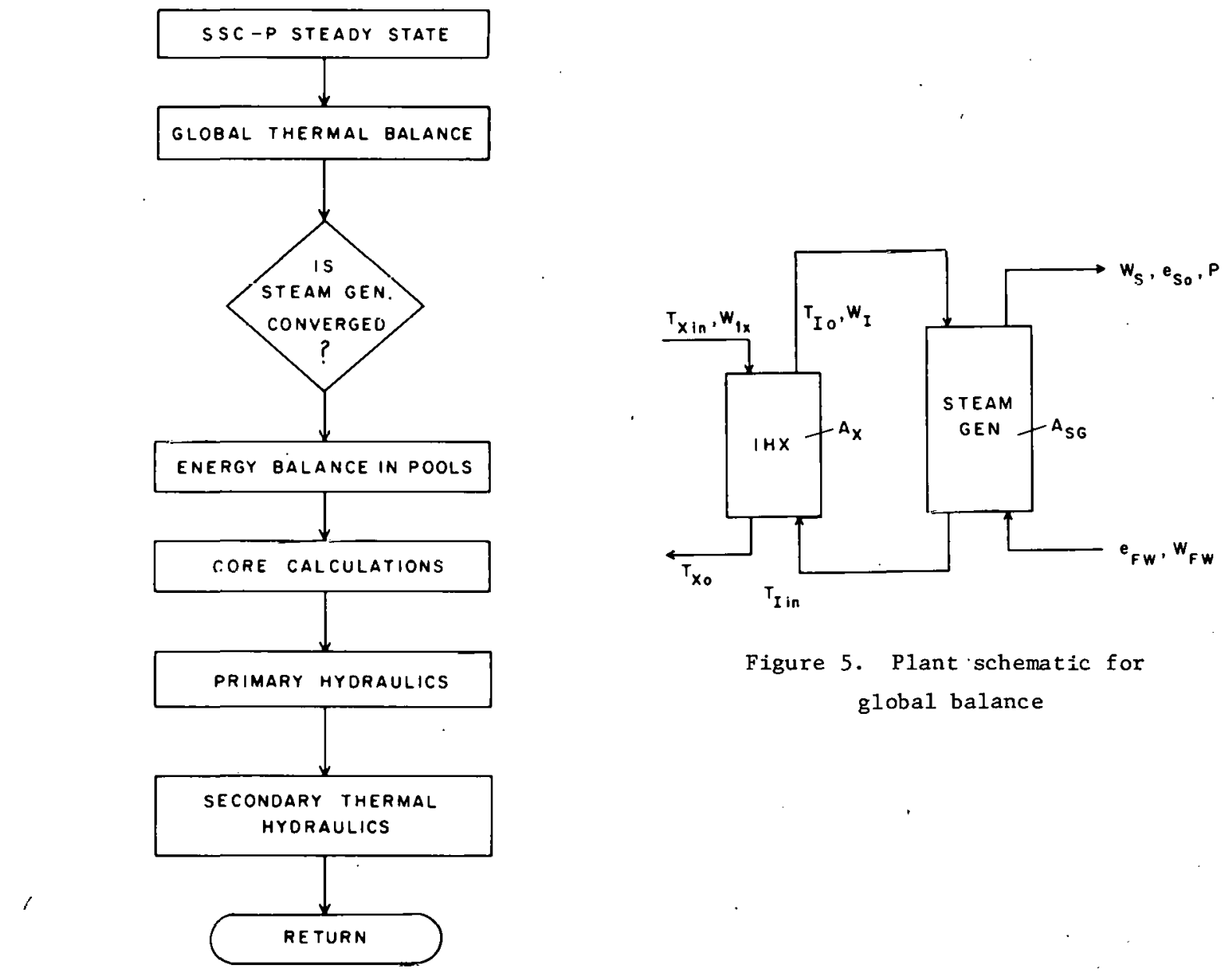

Figure 4. Logic for SSC-P overall steady-state solution 
where $\Delta T L M$ denotes the log-mean temperature difference. The sodium enthalpies are assumed to be functions of temperature only, while the water-side enthalpies are taken to be functions of both temperature and pressure. In Eqs. (3-2) and (3-4), $U_{X}$ and $U_{S G}$ are the overall heat transfer coefficients at the IHX and steam generator, respectively. In actual steady-state computations, these equations are replaced by a series of nodal heat balances, which constitute the detailed thermal models for the components.

In solving Eqs. (3-1) through (3-5), it is assumed that the heat transfer areas $A_{X}$ and $A_{S G}$ are known from the design. Also, the steam generator computational module presently assumes that

$$
e_{F}=f_{1}\left(W_{S}\right)
$$

and

$$
W_{S}=f_{2}(P S G)
$$

The relationships (3-6) and (3-7) are user-supplied input. Thus, the nine key plant variables to be determined are $P, W_{1 X}, T_{X} X_{n}, T_{X_{0}}, W_{I}, T_{I 0}, T_{I} i n$, eso, and $P_{S G}$. Five of these can be determined using Eqs. (3-1) through (3-5). The remaining four must be specified as input.

Since some confusion and uncertainty can arise on classifying an operating condition as known or unknown, the user is allowed some flexibility in the selection of plant variables which are input and those which are to be calculated. However, to keep the number of options within bounds, several constraints are placed on the choices. Since the reactor side and steam generator side contain the more important parameters from a plant design and operational point of view, the intermediate loop is left unspecified (i.e., to 
be calculated). Thus, $T_{I 0}, T_{I}$ in and $W_{I}$ may not be specified as input. Furthermore, since the total power (or power per loop $P$ ) is the prime variable, it is always assumed to be specified. The pressure at the module (e.g., evaporator, superheater) endpoints (PSG) is also assumed to be specified. With P and PSG assumed to be specified on input, only two more variables out of the remaining four (i.e., $W_{X}, T_{X_{i}}, T_{X_{0}}$, eso $)$ remain to be specified. This yields the following six combinations:

\begin{tabular}{|c|c|}
\hline Option & Parameters specified \\
\hline 1 & $W_{1 x}$, eso \\
\hline 2 & $T_{X_{0}}$, eso \\
\hline 3 & Txin, eso \\
\hline 4 & $T_{x i n}, w_{i x}$ \\
\hline 5 & $T_{x_{0}}, T_{x i n}$ \\
\hline 6 & $T_{x_{0}}, w_{1 x}$ \\
\hline
\end{tabular}

The user can select any of these options. The iterative schemes and calculation procedure for the various options are shown in Figure 6 .

Some of the changes in this flowchart as compared to the SSC-L flowchart are

i) $W_{1 X}$ replaces loop flow $W_{p}$ as the global variable.

ii) Once a converged intermediate loop power is obtained from the steam generator iteration loop, the power transferred per IHX is calculated from $P_{X}=P / n_{X}$. This power is then the convergent point for all options, for obtainting the IHX primary side parameters. This is required due to the presence or likelihood of more than one IHX per intermediate loop in the pool system.

iii) $T_{R_{i n}}$, $T_{R_{0}}$ can no longer be directly determined frọn $T_{X_{0}}, T_{X_{i n}}$, as part of the plant thermal balance because there is no direst piping 


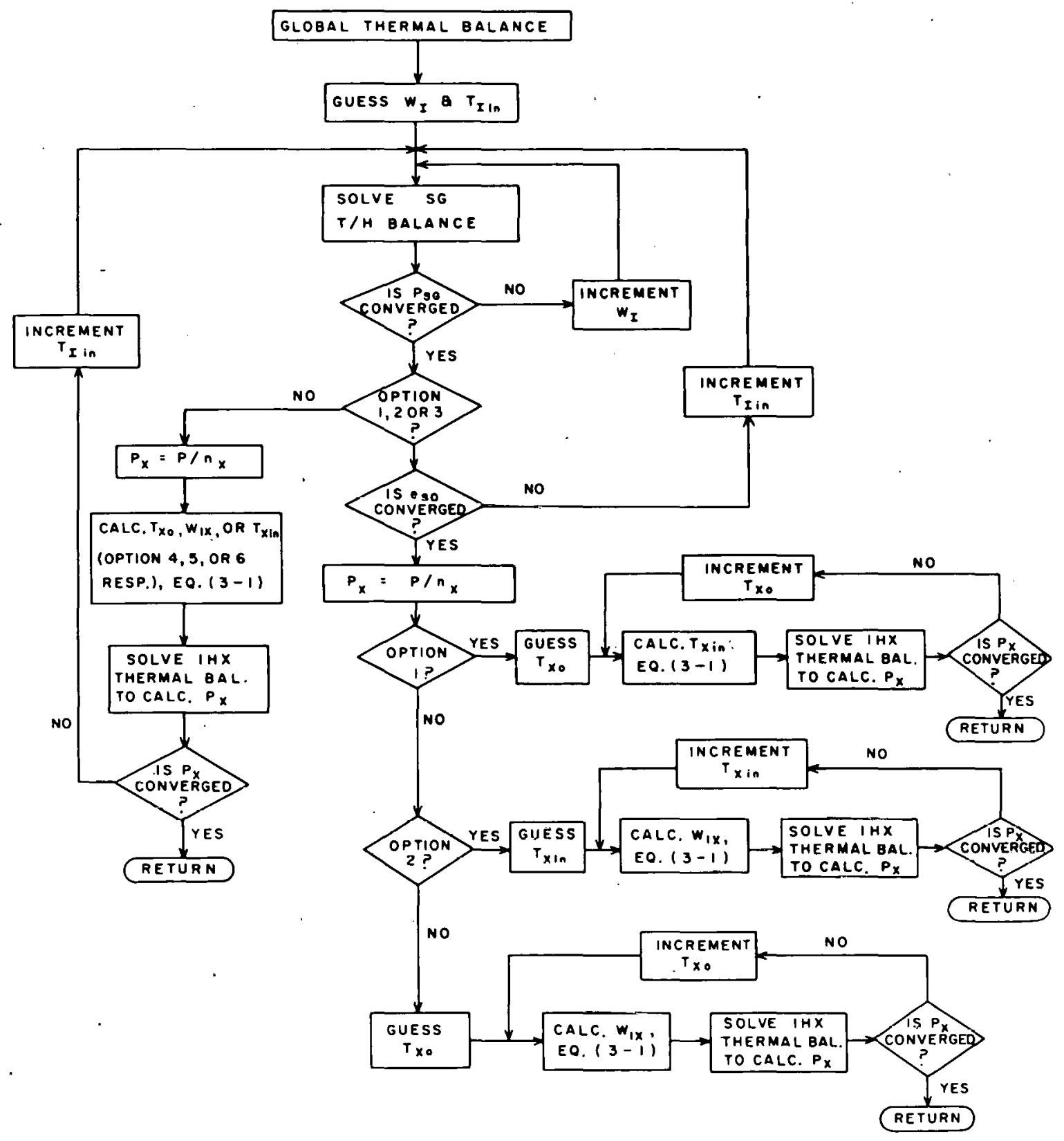

Figure 6. Iterative logic for global thermal balance 
connection between the reactor and $I H X$. Hence, T $X_{X_{0}}$, TXin replace TRin, $T_{\text {Ro }}$ as the global variables.

Note that the user can input approximate values for $T_{I i n}$, and $W_{I}$, and they will be used as initial guesses.

Equations to calculate flow through the core, external bypass and pump, knowing $W_{1} x$ and the external bypass fraction, have also been introduced as follows:

$$
\begin{aligned}
& w_{C}=n_{X} W_{1 X} \\
& w_{B P}=f_{B P} W_{C}
\end{aligned}
$$

and

$$
W_{P}=\left(W_{C}+W_{B P}\right) / n p
$$

These equations reflect the need to define individual component flow rates in the primary system due to the absence of well-defined loops. WBP is the bypass flow external to the core barrel. The Phenix design employs this concept, whereby a small precentage of core flow is allowed to leak below the core support structure and up around the cold pool to cool the main tank wall; more details will be given later.

\subsection{ENERGY BALANCE IN POOLS}

The components of the primary system required for energy balance are shown in Fig. 7. The main tank is covered by a roof generally welded to it. The coolant exiting the core mixes with the sodium in the hot pool. Conled sodium from the IHXs and external bypass. flow (if any) mix with the sodium in the cold pool. The hot and cold pools are physically separated by a thermal bar- 


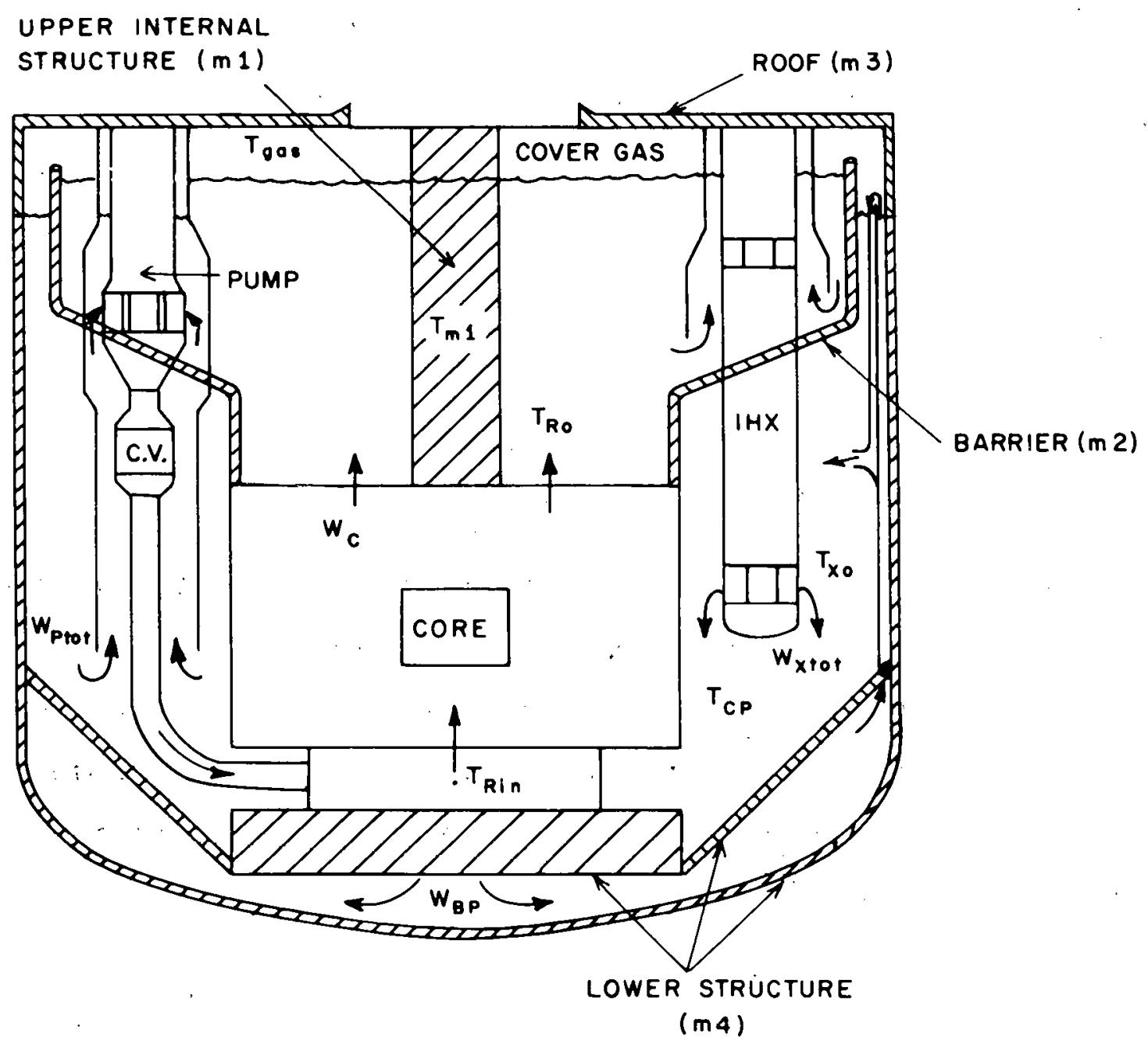

Figure 7. Primary system configuration for tank energy balance 
rier. However, their energy balances are coupled via heat transfer through this barrier. There is also heat transfer between the pool sodium and other structures and with the cover gas. All these processes have to be included in the energy balance for the sodium pools. The overall solution is determined in (Fig. 8).

As shown in Fig. 7, the instrument tree, control rod drive mechanism, control assembly, and other structures immersed in the hot pool are lumped together as a single mass $\mathrm{ml}$. The thermal barrier is denoted mass $\mathrm{m} 2$. The roof, together with the portion of tank wall exposed to cover gas, is denoted mass $\mathrm{m} 3$. In the cold pool, the core support structure and the tank wall in contact with the cold pool sodium are all lumped together as mass $\mathrm{m} 4$.

\subsubsection{Hot Pool Balance}

Energy balance in the hot pool is written as

$$
\begin{aligned}
W_{C} e_{R o}-n_{x} W_{1} e_{x i n}-U_{h g} A_{h g}\left(T_{H P}-T_{g}\right) & -U_{h m 2} A_{h m 2}\left(T_{H P}-T_{m 2}\right) \\
& -U_{h m 1} A_{h m 1}\left(T_{H P}-T_{m 1}\right)=0
\end{aligned}
$$

Here,

$$
\begin{aligned}
& e_{X i n}=e\left(T_{X i n}\right) \\
& e_{R_{0}}=e\left(T_{R_{0}}\right)
\end{aligned}
$$

Also, during steady state

$$
T_{H P}=T_{X i n}
$$

In the above equations, $T_{X} i_{n}, W_{1 X}$ and $W_{C}\left(=n_{X} W_{1 X}\right)$ are known from global thermal balance.

Other energy equations are 


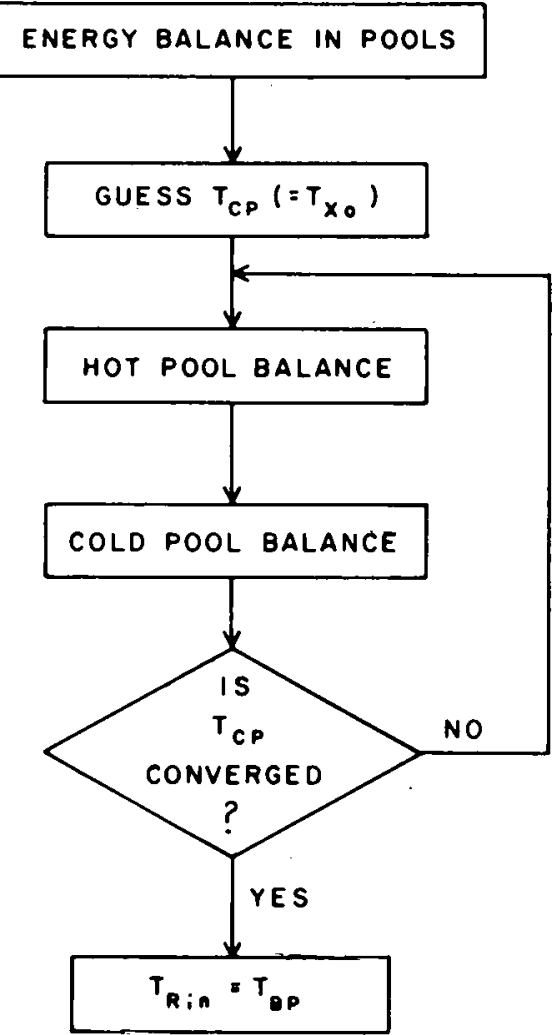

Figure 8. Driver logic for steady-state energy balance in the sodium pools (hot pool design) 
- Cover gas

$$
\begin{aligned}
U_{h g} A_{h g}\left(T_{H P}-T_{g}\right) & +U_{c g} A_{c g}\left(T_{C P}-T_{g}\right)-U_{g m 3} A_{d e c k}\left(T_{g}-T_{m 3}\right) \\
& +U_{g m 1} A_{g m 1}\left(T_{m 1}-T_{g}\right)=0
\end{aligned}
$$

Internal structure

$$
U_{h m l} A_{h m l}\left(T_{H P}-T_{m l}\right)-U_{g m l} A_{g m l}\left(T_{m l}-T_{g}\right)=0
$$

Barrier

$$
U_{h m 2} A_{h m 2}\left(T_{H P}-T_{m 2}\right)-U_{c m 2} A_{c m 2}\left(T_{m 2}-T_{C P}\right)=0
$$

$\underline{\text { Deck }}$

$$
U_{g m 3} A_{d e c k}\left(T_{g}-T_{m 3}\right)-U_{a m 3} A_{d e c k}\left(T_{m 3}-T_{a m b}\right)=0
$$

A complete specification of the hot pool requires determination of the seven variables $e_{R_{0}}, T_{m 1}, T_{m 2}, T_{m 3}, T_{H P}, T_{C P}$, and $T_{g}$. If $T_{C P}$ is known, six can be obtained using Eqs. $(3-11),(3-14)-(3-18)$. In the above equations the overall heat transfer coefficients $U_{h g}, U_{c g}, U_{g m 3}, U_{h m l}, U_{g m l}$, and $U_{a m 3}$ are all user-input constants. However, the coefficients for the barrier heat transfer are calculated by the code. Details on this, and area calculations, are provided in Section 3.2.4.

The solution procedure to determine the hot pool parameters, begins with guessing $\mathrm{T}_{\mathrm{CP}}$. The procedure is shown in the flow chart of Fig. 9. Note that if heat losses through the deck are neglected, Equation (3-18) can be dropped, and the term describing the heat transfer with the deck material can be excluded from the cover gas energy equation, Fq. (3-15) . Currently we assume that both the roof and tank are perfectly insulated from the outside environment. This assumption is reasonable for Phenix where the roof is covered by insulation followed by a nitrogen-filled gap between it and the 
BARRIER

HOT POOL BALANCE

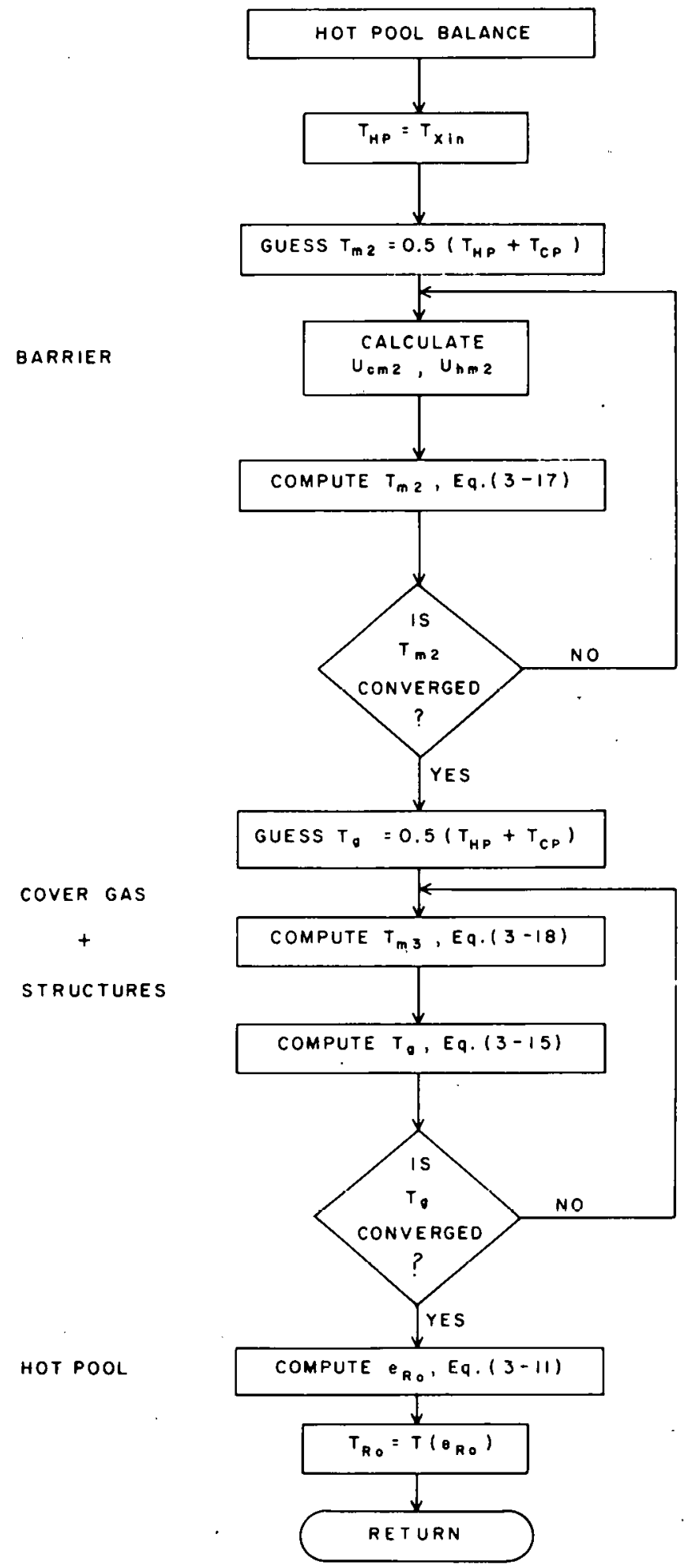

Figure 9. Logic for steady-state thermal balance in hot pool 
- shield deck; the main sodium tank wall is surrounded by an argon gas layer between it and the leak tank. For long-term transients, however, one should account for the impact of radiative heat losses to the water circuit surrounding the leak tank in Phenix.

\subsubsection{Cold Pool Balance}

Energy balance in the cold pool includes heat transfer to the barrier and cover gas. It also includes energy additions and subtractions due to IHX and external bypass flows entering and pump filow leaving the pool. Allowances are made in the formulation to include the possibility that some part of the IHX flow can directly stream into the pump suction without any mixing with the cold pool sodium. This is done through a user-specified fraction $B x$.

Under steady-state conditions, there is no net mass accumulation in the cold pool. Therefore, mass balance yields

$$
W_{B P}+n_{X} W_{X}=n_{P} W_{P}
$$

Energy balance in the cold pool can now be written as

$$
\begin{aligned}
& \left(1-B_{X}\right) n_{X} W_{X} e_{X}+W_{B P} e_{B P}+U_{C m 2} A_{C m 2}\left(T_{m 2}-T_{C P}\right) \\
& 1 U_{C g} A_{C g}\left(T_{g}-T_{C P}\right)-\left(W_{B P}+\left(1-B_{X}\right) n_{X} W_{X}\right) c_{C P}-0
\end{aligned}
$$

Here,

$$
e_{x 0}=e\left(T_{x 0}\right)
$$

and

$$
e_{B P}=e\left(T_{p_{i n}}+\Delta T_{p}\right)
$$


TXo is known from global thermal balance. Note that under steady-state conditions, the cold pool sodium is assumed to be in thermal equilibrium with the lower structural metal $\mathrm{m} 4$. The enthalpy of sodium entering the pump suction is obtained from

or

$$
\text { pWpepin }=B_{X} n_{X} W_{X} e_{X}+\left(W_{B P}+\left(1-B_{X}\right) n_{X} W_{X}\right) e_{C P}
$$

$$
e_{i n}=\left[n_{p} W_{p} e_{C P}+\beta_{X} n_{X} W_{X}\left(e_{X_{0}}-e_{C p}\right)\right] / n_{p} W_{p}
$$

Using the initial guess of $T_{C P}$, Eq. (3-20) is solved to get e $e_{C P}$. Thereafter, Eq. (3-20) is iterated on until a converged value of $e_{C P}$ is obtained, based on $T_{m 2}$ and $T_{g}$ determined from the hot pool thermal balance. The solution procedure is illustrated in Fig. 10.

\subsubsection{Barrier Heat Transfer}

The overall heat transfer coefficients $\left(U_{\mathrm{hm} 2}, U_{\mathrm{cm} 2}\right)$ for the barrier are evaluated assuming a multi-plate configuration with stagnant sodium or any other medium in between plates (see Fig. 11). 

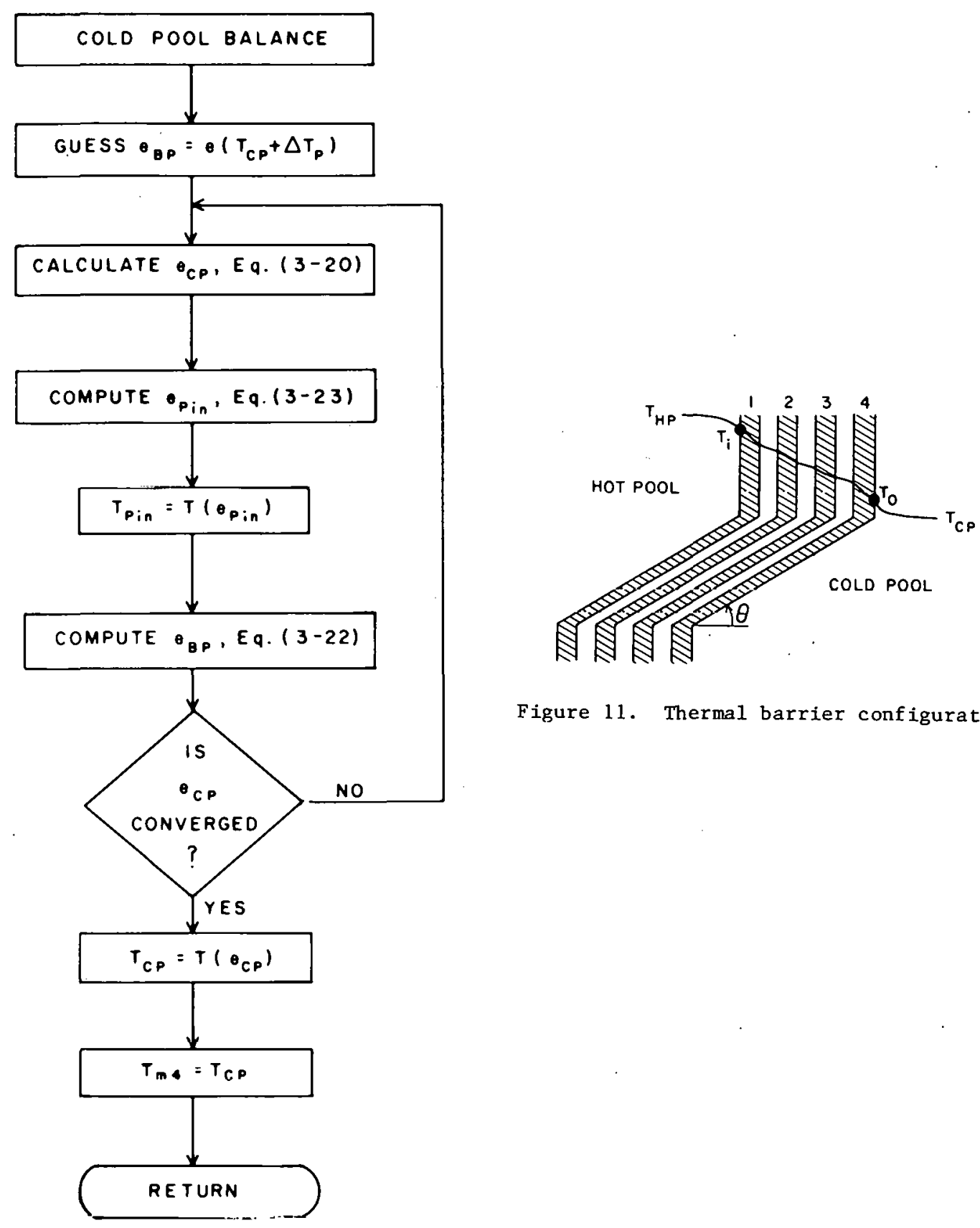

Figure 11. Thermal barrier configuration

Figure 10. Solution procedure for thermal balance in cold pool 
The model is developed, assuming the following:

(i) Sodium (or other medium) between plates is stagnant i.e., there is only conduction heat transfer.

(ii) The plates have the same thickness and are equidistant from each other.

(iii) The overall heat transfer coefficients for the composite structure can be calculated using the flat plate assumption.

(iv) There is no axial temperature variation in the barrier, i.e., radial conduction only.

(v) The properties are based on the average barrier temperature.

Let $N_{p}$ be the number of plates, $T_{m 2}$ the average temperature in the barrier, and $q$ the power transferred, in watts, through the barrier.

From the concept of thermal resistances, we can write:

$$
\frac{1}{U_{h m 2}}=\frac{1}{h_{i}}+\left(\frac{N_{p}}{2}\right) \frac{\delta_{s}}{k_{s}}+\left(\frac{N_{p}-1}{2} \frac{\delta_{N a}}{k_{N a}}\right)
$$

and

$$
\frac{1}{U_{\mathrm{cm} 2}}=\frac{1}{h_{0}}+\left(\frac{N_{p}}{2}\right) \frac{\delta_{s}}{k_{s}}+\left(\frac{N_{p}-1}{2}\right) \frac{\delta_{N a}}{k_{N a}}
$$

The power transfer q can be expressed in terms of the surface heat transfer coefficients $h_{j}, h_{0}$ as

$$
q=h_{j} A_{h m 2}\left(T_{H P}-T_{j}\right)
$$

and

$$
q=h_{0} A_{C m 2}\left(T_{0}-T_{C P}\right)
$$


- In terms of the composite barrier resistance, excluding the surface (film) coefficients $h_{j}, h_{0}$ :

$$
q=\left(T_{i}-T_{0}\right) / R_{T}
$$

where

$$
R_{T}=\frac{1}{A_{\text {barr }}}\left[N_{p} \frac{\delta_{s}}{k_{s}}+\left(N_{p}-1\right) \frac{\delta_{N a}}{k_{N a}}\right]
$$

There are five unknowns $U_{h m 2}, U_{c m 2}, T_{i}, T_{0}, q$. (provided $h_{j}, h_{0}$ can be determined as functions of the temperatures $T_{j}, T_{0}$, respectively). All five can be determined using Eqs. (3-24) through (3-28). The solution procedure is illustrated in Fig. 12 .

\subsubsection{Areas}

The barrier is allowed to be composed of two or more parts, (see Fig. 13) one inclined at an angle $\theta$ to the horizontal, and the others vertical. $\theta$ can vary, depending on the barrier design. For Phenix, $\theta=19^{\circ}$. 


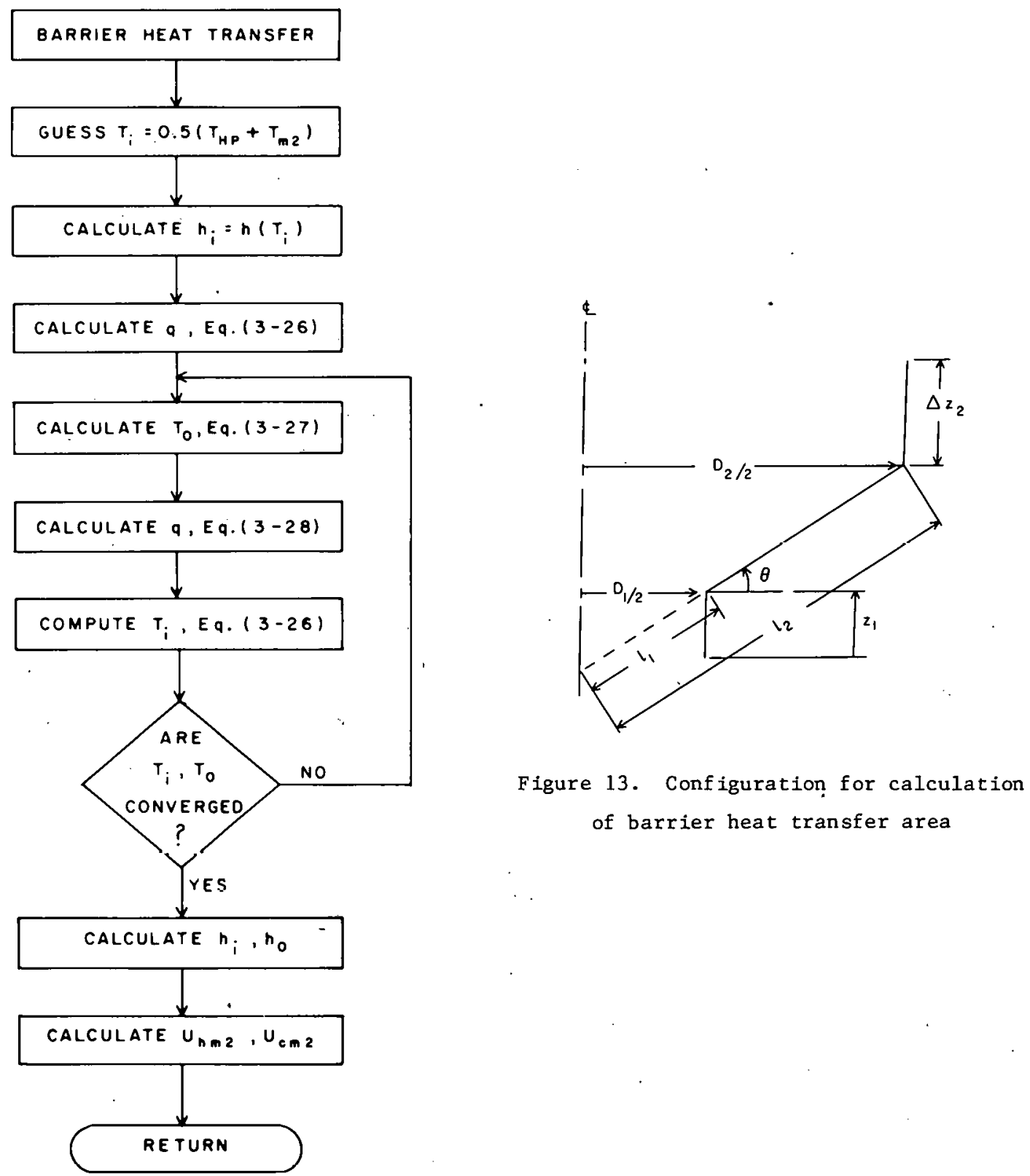

Figure 12. Logic to calculate overall barrier heat transfer coefficients 
The surface area of the inclined redan is

$$
\begin{aligned}
A_{\text {incl }} & =\frac{\pi}{2}\left(D_{2} \ell_{2}-D_{1} \ell_{1}\right) \\
& =\frac{\pi}{4 \cos \theta}\left(D_{2}^{2}-D_{1}^{2}\right)
\end{aligned}
$$

where $D_{1}, D_{2}$ are user-input dimensions.

$$
A_{\text {vert }}=\pi D_{1} z_{1}+\pi D_{2} \Delta z_{2}
$$

Then,

$$
A_{\text {hm2 }}=A_{c m 2}=A_{\text {incl }}+A_{\text {vert }}=A_{\text {barr }}
$$

An option is provided in the code which allows the user to either

(i) input $A_{\text {incl }}, A_{\text {vert }}, A_{\text {barr }}$

or

(ii) input $D_{1}, D_{2}, \theta, z_{1}$, and $\Delta z_{2}$, in which case the code calculates the areas.

\subsubsection{Film Coefficients:}

Equation (3-26) can be rewritten as

$$
q=h_{\text {vert }} A_{\text {vert }}\left(T_{H P}-T_{j}\right)+h_{i n c l} A_{i n c l}\left(T_{\text {IIP }}-T_{j}\right)
$$

Combining Eqs. (3-28), (3-29), we get

$$
h_{i}=\left(h_{\text {vert }} A_{\text {vert }}+h_{i n c l} A_{i n c l}\right) / A_{h m 2}
$$

Equation (3-34). also holds for $h_{0}$. 
$h_{\text {vert }}, h_{i n c l}$ are obtained from established correlations for Nusselt number.

$h_{\text {vert }}$

For laminar boundary layer flow over a vertical flat plate immersed in a body of liquid, Eckert ${ }^{10}$ derived

$$
N u_{x}=0.508\left[\frac{G r_{x} P r^{2}}{0.952+P r}\right]^{0.25}
$$

For $\operatorname{Pr} \rightarrow 0$, this becomes

$$
N u_{x}=0.514 \operatorname{Ra}_{x}{ }^{0.25} \operatorname{Pr} 0.25 \text { for } \operatorname{Ra} \leq 10^{8}
$$

But.

and

$$
\bar{h}=\frac{\int_{0}^{L} h_{x} d x}{L}
$$

$$
N u_{x}=\frac{h_{x} x}{k} ; G r_{x}=\frac{g \beta x^{3} \Delta T}{v^{2}}
$$

Substituting Eq. (3-38) into (3-27) and integrating yields

$$
\overline{N u}=\frac{4}{3} N u_{x}
$$

or

$$
\overline{\mathrm{Nu}}=0.685 \mathrm{Ra}^{0.25 \mathrm{Pr} 0.25} \quad \mathrm{Ra} \leq 10^{8}
$$

For turbulent flow, Eckert ${ }^{11}$ derived:

$$
N u_{x}=0.0295\left[\frac{\mathrm{Pr}^{7 / 6} \mathrm{Gr}_{\mathrm{x}}}{1+0.494 \mathrm{Pr}^{2 / 3}}\right]^{2 / 5} \quad \begin{aligned}
& \mathrm{Gr}>10^{8} \\
& \mathrm{Ra}>10^{8}
\end{aligned}
$$


For $\mathrm{Pr} \rightarrow 0$

$$
N u_{x} \simeq 0.0295 \mathrm{Pr}^{0.467} \mathrm{Gr}_{\mathrm{X}}{ }^{0.4}
$$

Evaluating average $\mathrm{Nu}$ as before gives

or

$$
\mathrm{Nu}=0.833 N u_{x}
$$

$$
\begin{array}{ll}
\mathrm{Nu}=0.025 \mathrm{Pr}^{0.467} \mathrm{Gr}^{0.4} & \mathrm{Gr}>10^{10} \\
& \mathrm{Ra}>10^{8}
\end{array}
$$

Here, for either the hot pool side or the cold pool side, we have

$$
G r_{j}=g\left(\rho_{i}-\rho_{H P}\right) L_{v e r t}^{3} / \rho_{j} \nu_{i}^{2}
$$

and

$$
G r_{0}=g\left(\rho_{C P}-\rho_{0}\right) L_{\text {vert }}^{3} / \rho_{0} \nu_{0}^{2}
$$

Also,

$$
\mathrm{Ra}=\mathrm{Gr} \mathrm{Pr}
$$

and

$$
v=\mu / \rho
$$

$\mathrm{h}_{\mathrm{incl}}$

The same cquations derived above, are used for $h_{i m l}$, except that $L_{\text {vert }}$ in the formulation for Grashof number is

$$
L_{\text {vert }}=L_{\text {incl }} \sin \theta
$$

A study was made to evaluate the sensitivity of the barrier overall heat transfer coefficients to temperature, e.g., $U_{h m 2}$ to $T_{m 2}$ and $T_{H P}$; an option has been added to the code that allows the user to specify $U_{\mathrm{hm} 2}$ and 
$\mathrm{U}_{\mathrm{cm} 2}$, altogether bypassing the barrier heat transfer calculations. These coefficients would then remain constant during transient computations.

Another option being considered is to allow the user to specify a higher sodium thermal conductivity between plates to represent an active barrier, i.e., where sodium between plates is moving causing convective heat transfer.

\subsection{PRIMARY HYDRAULICS}

The steady-state hydraulic calculations in the primary system involve the determination of pressure losses (or gains) in the different components, pump operating head and speed, liquid levels in the primary tank, and the absolute pressures at important locations in the circuit. The flow rates have already been determined through global thermal balance. Figure 14 shows the hydraulic profile of the primary tank and components. The overall steady-state logic for the primary hydraulic calculations is presented in Fig. 15. The logic includes both hot and cold pool design concepts. Note that for the cold pool design, both thermal and hydraulic balances are performed simultaneously bypassing the energy balance in the pools. Since the commercial pool LMFBR will most likely be of the hot pool concept, the first version of SSC-P has been developed to simulate the hot pool concept.

\subsubsection{Intermediate Heat Exchanger}

During steady-state conditions, the volume-averaged momentum equation reduces to

Pressure drop, i.e., $P_{i n}-P_{0}=$ pressure losses. 


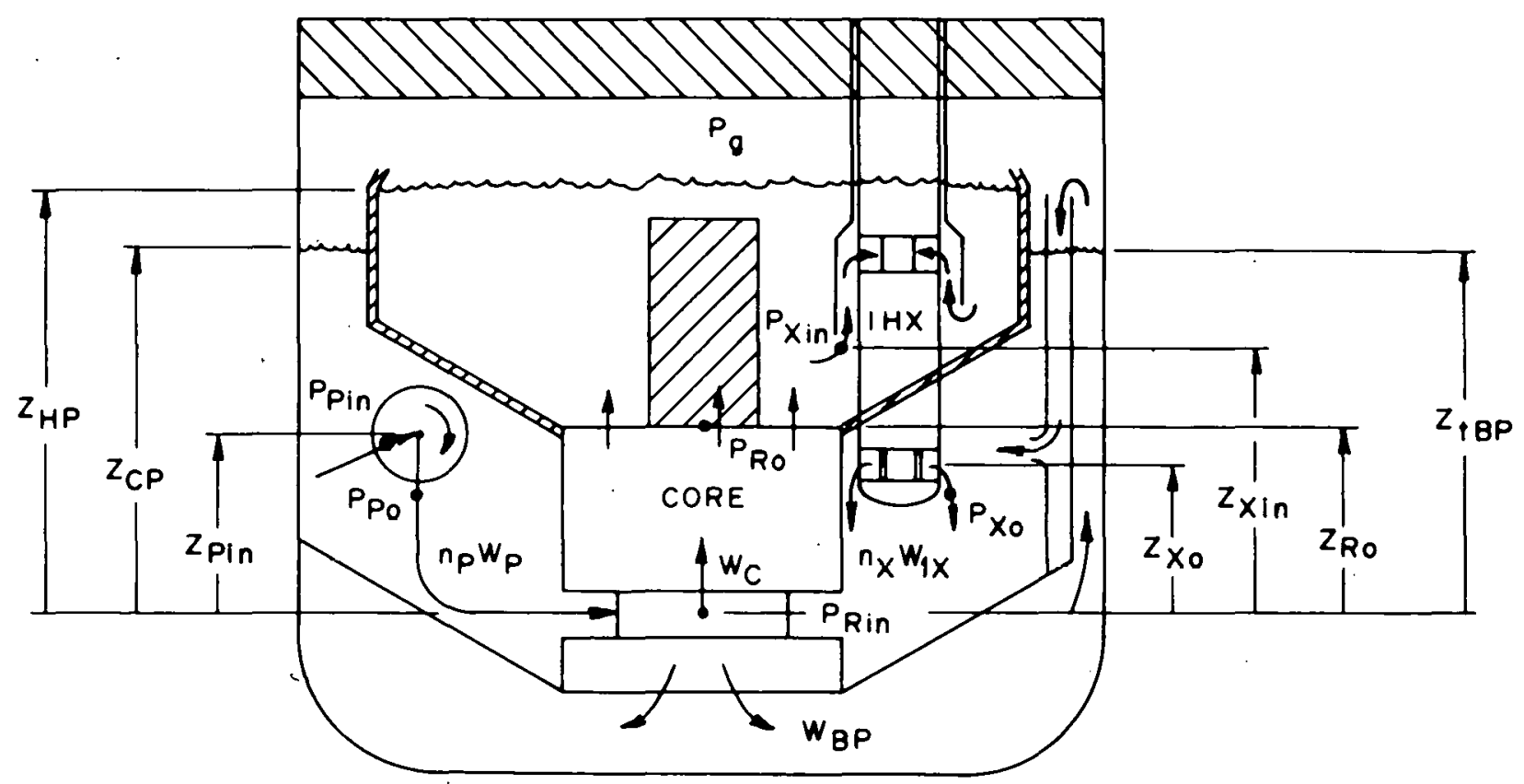

Figure 14. Hydrallic profile of primary tank and components 


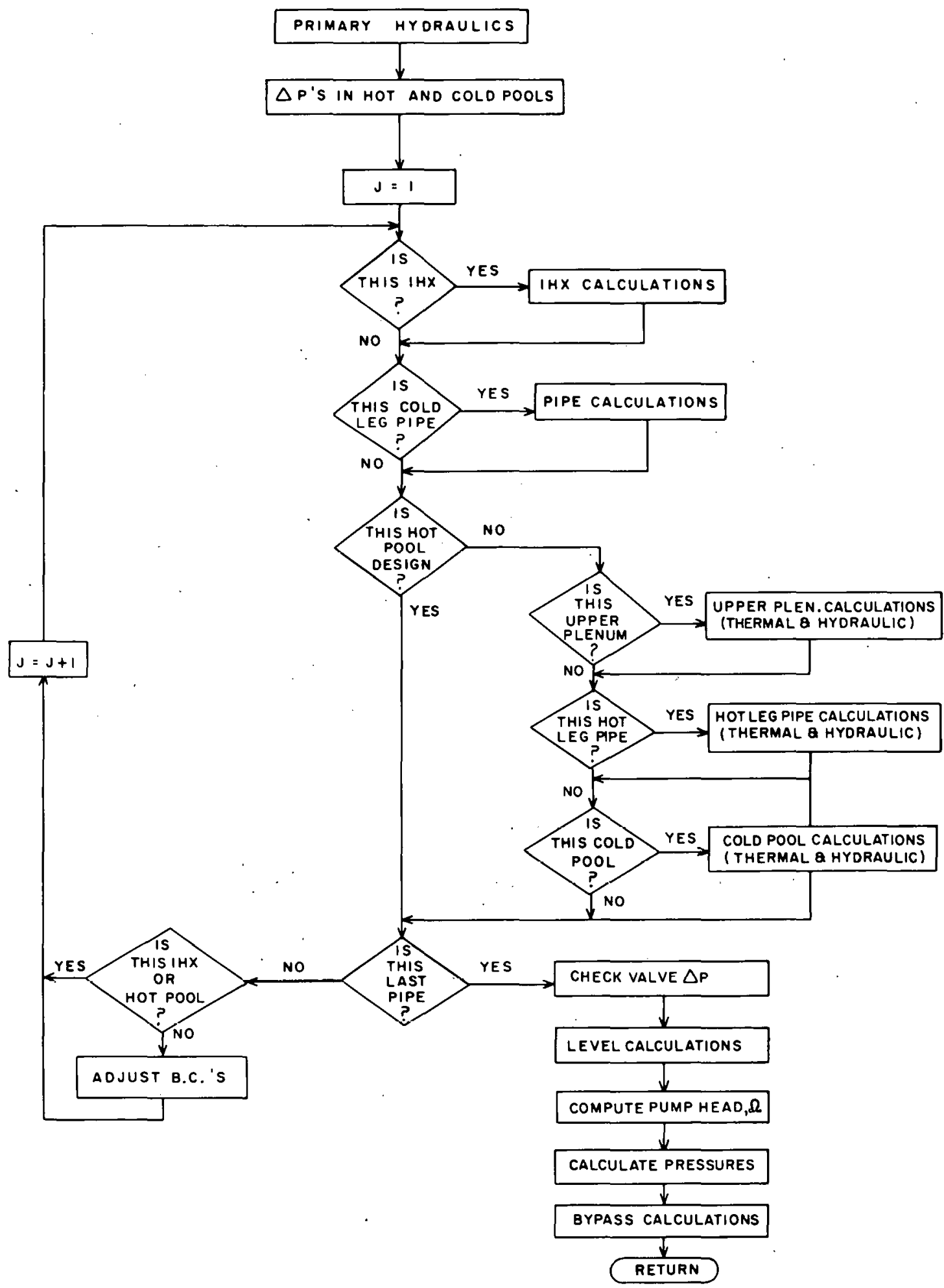

Figure 15. Steady-state logic for primary hydraulic calculations 
For the IHX, the sum of losses in either the primary or secondary side, is expressed as

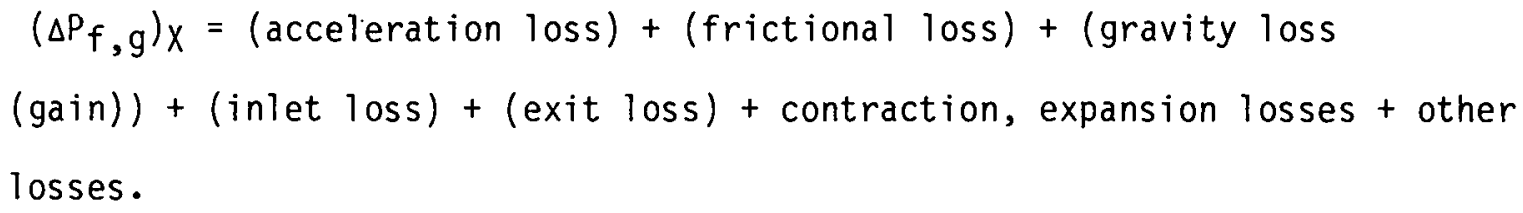

Note that a negative value obtained for gravity loss indicates a gain. Other losses are expressed as

$$
\Delta \mathrm{P}_{\text {other }}=\frac{\mathrm{K}_{1 \mathrm{X}} \mathrm{W}_{1 \mathrm{X}}\left|\mathrm{W}_{1 \mathrm{X}}\right|}{\mathrm{PA} 1 \mathrm{X}}
$$

for the primary side, and similarly for the secondary side.

In most cases, the IHX pressure drop corresponding to full flow conditions is known a priori, through flow model testing performed by the manufacturer. However, this pressure drop may correspond only to losses with the unit placed in a horizontal position, for which effects of gravity are not included. For this reason, in the option where $k_{1 X}$ is either specified or calculated by the code, the following equation is used:

$$
\Delta P_{1 X}=\Delta P_{\text {acc }}+\Delta P_{f}+\Delta P_{i n}+\Delta P_{c, e}+\Delta P_{\text {other }}
$$

Earlier, in the SSC-L formulation, the right hand side of Equation (3-5I) included gravity. The user should exercise caution when specifying the value of $\Delta P_{1 X}$ if known, to ensure that it does not already include the gravity term. The code adds on the gravity term to give the final value of $\Delta P_{1 X}$ for the hydraulic calculations. Further details on the forilulation have been reported earlier, and will not be presented here. 


\subsubsection{Cold Leg Piping}

The pressure loss calculation during steady-state consists of combining the losses due to friction and gravity, and losses due to bends, fittings, etc. The coefficient representing the latter loss is always user-specified. Note that the length and elevation changes assigned to the piping include the elevation changes, if any, occurring across the pump $\left(\Delta z_{p}\right)$ and check valve $(\Delta z C V)$, while those components are treated as point volumes.

\subsubsection{Liquid Levels in Pools}

From Fig. 14 we can write, from static balance:

$$
\begin{aligned}
& P_{X i n}=P_{g}+\rho_{H} g\left(Z_{H P}-Z_{X i n}\right)- \\
& P_{X_{0}}=P_{g}+{ }_{{ }_{C}} g\left(Z_{C P}-Z_{X_{0}}\right)
\end{aligned}
$$

Subtracting Eq. (3-53) from Eq. (3-52) and rearranging yields the sodium level in the cold pool as

$$
Z_{C P}=\left[\rho_{H}\left(Z_{H P}-Z_{X_{i n}}\right)-\frac{\Delta P_{1 X}}{g}+\rho_{C} Z_{X_{0}}\right] / \rho_{C}
$$

The level in the hot pool, $Z_{H P}$, is assumed known, along with IHX elevations $Z_{X}$ in and $Z_{X_{0}}$. Note that here $\Delta P_{1 X}$ is the value provided by the $I H X$ hydraulic calculations and includes the gain in pressure due to gravity as the primary coolant moves downward in the unit.

The volume of cover gas is obtained simply as

$$
v_{g}=\left(Z_{\text {tank }}-Z_{H P}\right) A_{h g}+\left(Z_{\text {tank }}-Z_{C P}\right) A_{C g} \cdot
$$


where $A_{h g}, A_{c g}$ are the areas of hot pool and cold pool in contact with the cover gas, respectively.

For a cold-pool concept, only one liquid level exists, and the volume of cover gas would simply be equal to $\left(Z_{\text {tank }}-Z_{C P}\right) A_{C g} \cdot$

The mass of cover gas blanket is obtained, assuming the perfect gas law, as

$$
m_{g}=P_{g} V_{g} / R_{g} T_{g}
$$

\subsubsection{External Bypass}

The code models external bypass flow, a small fraction of the total pump flow that may be allowed to leak down from the core inlet plenum region and up between the outer baffle and the tank wall (see Fig. 14).

The calculations are set up to allow bypass flow to be evaluated dynamically during a transient. With steady-state core flow and external bypass fraction known, the loss coefficient is calculated to account for all losses occurring in the bypass region. The formulation is described below. Momentum balance reduces to:

$$
\Delta P_{B P}=\rho_{C} g\left(Z_{B P O}-Z_{B P i n}\right)+\frac{K_{B P} W_{B P}{ }^{2}}{{ }_{C}}
$$

Since the bypass flow originates at the reactor inlet, $Z_{B P}$ in is zero. Rearranging Equation (3-57) yields

$$
K_{B P}=\left(\Delta P_{B P}-\rho_{C} g Z_{B P O}\right) \rho_{C} / W_{B P}^{2}
$$

Here,

$$
\Delta P_{B P} \equiv P_{B P i n}-P_{B P O}
$$

and

$$
\text { PBPin = PRin, }
$$




$$
P_{B P_{0}}=P_{g}+\rho_{C} g\left(Z_{C P}-Z_{B P_{0}}\right)
$$

The loss coefficient $K_{B P}$ in Equation (3-58) is held constant to enable computation of $W_{B} P$ during the transient.

\subsubsection{Pressure Drops in the Pools}

The pressure drop experienced by the coolant in the hot pool from the core out let to the IHX inlet is simply

$$
\Delta P_{H P}=\rho_{H} g\left(Z_{x i n}-Z_{R O}\right)
$$

In the cold pool, the pressure drop between the IHX outlet and pump inlet is formulated as

$$
\Delta P_{C P}=\rho_{C} g\left(Z_{P i n}-Z_{X_{0}}\right)+K W_{P}{ }^{2} / \rho_{C} A^{2}
$$

The additional term in Eq. (3-62) accounts for any losses occurring as the fluid is forced to turn. In Phenix, for example, there is an annulus surrounding the pump inlet and extending downwards in the pool. Its apparent purpose is to minimize the impact of cold pool stratification (during IHX undercooling events) on the inlet temperature to the core. In PFR, the coolant emerging from the IHX is distributed around the heat exchanger shell

and sweeps the tank surface before flowing to the pump suction. In this way, the risk of hot-sodium stratification is reduced.

\subsubsection{Pumps}

The sodium pumps used in pool-type LMFBRs as in the loop type are also vertically mounted, variable speed, centrifugal units. In the pump model 
developed for SSC-L, ${ }^{12}$ the impeller behavior is characterized by homologous head and torque relations encompassing all regions of operation. The homologous characteristics were derived from independent model test results with a centrifugal pump of specific speed $\left(N_{S}\right)$ equal to 35 (SI units), and are applicable to LMFBR pumps in general.

The model was shown to give very good agreement with measured data for FFTF pumps $\left(N_{S} \simeq 27.2\right)$, and with vendor calculations for the CRBR pump $\left(N_{S} \simeq 42.8\right)$. It is not anticipated therefore, that the characteristic coefficients built into the code will need to be changed for future applications, unless a pump is encountered with $N_{S}$ drastically higher or lower than 35. The primary and secondary pumps in Phenix have a specific speed of approximately 36 (SI units). Details on the procedure for obtaining pump head and speed can be found in Ref. 13 . 


\section{TRANSIENT MODELS}

\subsection{PRIMARY COOLANT DYNAMICS}

The dynamic response of the primary coolant in a pool-type LMFBR, particularly the hot pool concept, can be quite different from response in the loop-type LMFBR. This difference arises primarily from the lack of direct piping connections between components in the hot and cold pools (see Fig. 14). Even though there are free surfaces present in the reactor vessel and pump tank of loop-type designs, the direct piping connections permit the use of basically a single flow equation to characterize the coolant dynamics in the primary loop, except in a transient initiated by a pipe rupture or similar asymmetric initiator. In the pool-type designs under discussion where both hot and cold pools are free surfaces there is direct mixing of the coolant with these open pools prior to entering the next component, two different flows would have to be modeled to characterize the coolant dynamics of the primary system. During steady-state the two flow rates are related by a simple algebraic equation. During a transient, however, the flow in the up-leg from the pump would respond to the pump head and losses in that circuit including losses in the core; the IHX flow would respond to the level difference between the two pools, as well as losses and gravity gains in the unit. The gravity gain could be significant for low-flow conditions, particularly if the IHX gets overcooled due to a mismatch of primary and secondary flows.

In addition to the above considerations, the number of heat exchangers, $n_{X}$, is a design choice and can be expected to be different from the number of pumps, np. The number $n_{X}$ is determined by pressure drop and thermal 
rating per unit requirements. Also, the number of primary pumps is independent of the number of secondary loops in both hot pool and cold pool concepts; there is no pipe connection in the cold pool. The Phenix plant has three pumps and six IHXs operating in parallel. For symmetric transients, such as a loss-of-electric power (LOEP) event, all parallel components can be expected to behave identically, and only one flow equation needs to be modeled for each set of parallel components. However, in cases of asymmetric events, it is necessary to distinguish between the components that are directiy affected by the postulated accident from those that are not. Examples of such events are a pipe rupture in a pump discharge line to the reactor, a single pump malfunction or a malfunction in an intermediate circuit causing the affected IHXs to behave differently from the others.

\subsubsection{Flow Equations}

We introduce the concept of flow paths $\left(N_{\text {path }}\right)$, which defines the number of pump or IHX flow equations to be solved. In each flow path, we can lump a number of IHXs $\left(F_{X}(k), k=1, N_{\text {path }}\right)$ and a number of pumps $\left(F_{p}(k), k=1, N_{\text {path }}\right)$ that are expected to have the same reaction to the transient.

\subsubsection{Intact system}

For an intact system, volume-averaged equations can be written for $k=1$ to Npath, as follows:

Pump flow

$$
\frac{d W_{p}(k)}{d t} \sum_{P} \frac{L}{A}(k)=P_{P_{0}}(k)-P_{R i n}-\sum_{P} \Delta P_{f, g}(k)
$$


$\underline{\text { IHX flow }}$

$$
\frac{d W_{1 X}(k)}{d t} \sum_{X} \frac{L}{A}(k)=P_{X i n}-P_{X_{0}}-\sum_{X} \Delta P_{f, g}(k)
$$

Note that for symmetric transients, there is only one flow path, hence only one flow equation for each component: In the case of a single pump malfunction, two paths would have to be modeled. The first path would have the damaged pump and an IHX, and the second path would include the remaining pumps and IHXs.

In the above equations, $\mathrm{P}_{\mathrm{P}_{0}}$, the pump exit pressure, is obtained from

$$
P_{\text {Po }}=P_{\text {Pin }}+\rho_{\text {in }} g H
$$

where $H$ is the pump head, obtained from the pump characteristics . The IHX terminal pressures are obtained from static balance as

$$
\begin{aligned}
& P_{X_{i n}}=P_{g}+o_{H} g\left(Z_{H P}-Z_{X_{i n}}\right) \\
& P_{X_{0}}=P_{g}+\rho_{C} g\left(Z_{C P}-Z_{X_{0}}\right)
\end{aligned}
$$

The reactor inlet pressure, $P_{R i n}$, is obtained from a complicated algebraic equation (see Section 4.1.4 for derivation).

\subsubsection{Damaged System}

In case of pipe rupture (for the hot pool concept, this can only happen in the pump discharge line to the reactor), Eq. (4-1) gets modified, for the broken path, to

$$
\frac{d W_{P}}{d t} \sum_{\text {uob }} \frac{L}{A}=P_{P o}-P_{b i n}-\sum_{\text {uob }} \Delta P_{f, g}
$$


An additional equation is needed to describe the flow downstream of the break:

$$
\frac{d W_{p}}{d t} \sum_{d o b} \frac{L}{A}=P_{b o}-P_{R i n}-\sum_{d o b} \Delta P_{f, g}
$$

Some discussion of the formulation for a generic cold pool design is presented in a later section. The inlet and outlet pressures at the break location, $\mathrm{P}_{\mathrm{bin}}$ and $\mathrm{P}_{\mathrm{bo}}$, respectively, are calculated by the break model. Details of the model can be found in an earlier report ${ }^{14}$. The pressure external to the break, which is needed to compute these pressures, is obtained from a static balance as

$$
P_{\text {ext }}=P_{g}+\rho_{c} g\left(Z_{C P}-Z_{b}\right)
$$

This is also the back pressure opposing the flow out of the break. Eq. (4-8) yields a much larger value for Pext when compared to loop-type designs (where it is generally equal to atmospheric pressure, unless the break occurs within a guard vessel, in which case it would remain atmospheric until the vessel fills to the break elevation). This is a contributing factor to the less serious nature of pipe break accidents in pool-type LMFBR designs. Another contributing factor is the generally low hydraulic resistances through the core and IHX, allowing higher core flow from the intact flow paths, relative to the loop design.

\subsubsection{Liquid Levels in Pools}

During steady-state, the level difference between hot and cold pools supports the net losses occurring in the intermediate heat exchanger, thereby maintaining flow through it. A high level difference would be necessary to drive flow through a high pressure drop unit. Hence, this dictates the 
requirement of low pressure drop units for these designs. During transient conditions, any reduction in IHX losses alone will tend to increase flow through it. However, this will also reduce the level difference driving the flow. This competition between two opposing forces determines the dynamic state of levels and flow through the IHX. During flow coastdown transients, the levels approach each other, implying a net increase of cold pool mass at the expense of the hot pool. When the levels restabilize under low flow conditions, the level difference once again maintains the IHX losses. While it is not generally expected that the liquid levels will cross each other, it has been seen analytically that if the IHX is overcooled due to very high intermediate flow, the resulting gravity head in the unit, available at much higher densities, is sufficient to overcome all frictional and other losses. The levels then eventually cross each other while the flow is maintained positive.

The total flow through all the IHXs and all the pumps can be determined from the summations

$$
W_{\text {Xtot }}=\sum_{k=1}^{N_{\text {path }}} F_{X}(k), w_{X}(k)
$$

and

$$
W_{\text {Ptot }}=\sum_{k=1}^{N_{\text {path }}} F_{p}(k) W_{p}(k)
$$

Mass balance at the cold pool gives

$$
A_{c g} \frac{d}{d t}\left(\rho_{C} Z_{C P}\right)=W_{X \text { tot }}-w_{P t o t}+w_{B P}+W_{b}
$$

Note that $W_{b}$, the break flow, is zero for an intact system. Eq. (4-11) assumes that all the level changes likely to occur during a transient are confined to a constant cross-sectional area. 
Mass balance in the hot pool gives

$$
A_{h g} \frac{d}{d t}\left(\rho_{H} Z_{H P}\right)=W_{C}-W_{X \text { tot }}
$$

When equations (4-11) and (4-12) are solved simultaneously with the flow equations, the results yield the liquid levels $Z_{C P}$, $Z_{H P}$ during the transient.

\subsubsection{External Bypass}

The external bypass flow is dynamically described by the flow equation

$$
\frac{d W_{B P}}{d t} \sum_{B P} \frac{L}{A}=P_{R i n}-P_{B P o}-\Delta P_{g}-k_{B P} \frac{W_{B P 2}}{{ }^{P_{C}}} .
$$

Currently, the formulation has two restrictions:

(i) the flow is not allowed to reverse

(ii) no thermal interactions are represented

The former restriction can be removed, while the latter may not be significant to the system behavior.

As before,

$$
P_{B P_{0}}=P_{g}+\rho_{C} g\left(Z_{C P}-Z_{B P o}\right)
$$

and

$$
\Delta P_{g}=\mu_{R i n} g Z_{B H_{O}}
$$

$K_{B P}$ is the loss coefficient determined during plant initialization calculations. PRin is obtained from Eq. (4-23).

\subsubsection{Reactor Inlet Pressure}

Due to the tight hydraulic coupling of the reactor inlet with the rest of 
the primary system, the solution of the system flow equations, as well as coolant dynamics in the core, requires the reactor inlet pressure, $P_{\text {Rin }}$, to be known at all times.

In the following sections, the equation used to calculate $P_{R}$ in is derived for both an intact and a damaged system.

\subsubsection{Intact System}

Mass conservation at the reactor inlet yields

$$
W_{C}=\sum_{k} F_{P}(k) W_{P}(k)-W_{B P}
$$

Differentiating both sides gives

$$
\frac{d W_{C}}{d t}=\sum_{k} F_{p}(k) \frac{d W_{P}}{d t}(k)-\frac{d W_{B P}}{d t}
$$

The core flow can be expressed in terms of channel flows as

$$
w_{C}=\sum_{j=1}^{N_{r h}} w_{j}
$$

where $N_{c h}$ represents the number of channels simulated in the core. Differentiating both sides, we get

$$
\frac{d w_{C}}{d t} \sum_{j} \frac{d w_{j}}{d t}
$$

Furthermore, for each channel $\mathrm{j}$ we can write, from momentum balance

$$
\frac{d W_{j}}{d t}\left(\sum \frac{L}{A}\right)_{j}=P_{R i n}-P_{R o}-\left(\sum \Delta P_{f, g}\right)_{j}
$$

where

$$
P_{R O}=P_{g}+\rho_{H} g\left(Z_{H P}-Z_{R o}\right) .
$$


Combining Eqs. $(4-17),(4-19)$ and $(4-20)$ gives

$$
\sum_{k} F_{P}(k) \frac{d W_{P}}{d t}(k)-\frac{d W_{B P}}{d t}=\sum_{j} \frac{P_{R i n}-P_{R o}-\left(\sum \Delta P_{f, g}\right)_{j}}{\left(\sum \frac{L}{A}\right)_{j}} \quad \text { (4-22) }
$$

Substituting Eqs. (4-1) and (4-13) into the left hand side of Eq. (4-22) and simplifying yields the reactor inlet pressure as

$$
P_{\text {Bin }}=(A+B+C) /(D+E+F)
$$

where

$$
\begin{aligned}
& A=\sum_{j}\left[\frac{P_{R o}+\left(\sum \frac{L}{A}\right)_{j}}{\left(\sum \frac{L}{A}\right)_{j}}\right] \\
& B=\sum_{k} F_{P}(k)\left[\frac{P_{P_{0}}(k)-\sum_{P} \Delta P_{f, g}(k)}{\sum_{P} \frac{L}{A}(k)}\right] \\
& C=\left(\frac{P_{B P_{0}}+\Delta P_{g}+K_{B P} W_{B P}^{2} / \rho_{C}}{\sum_{B P} \frac{L}{A}}\right) \\
& D=\sum_{j} \frac{1}{\left(\sum \frac{L}{A}\right)_{j}} \\
& E=\sum_{k} \frac{F_{p}(k)}{\sum_{P} \Delta P_{f, g}(k)} \\
& F=\quad-\frac{1}{\sum_{B P} \frac{L}{A}}
\end{aligned}
$$

$-45-$ 


\subsubsection{Damaged System}

In case of a pipe rupture in one of the pump discharge lines, mass conservation at the reactor inlet has to account for one of the flows which is the break to the reactor. Thus,

$$
W_{C}=\sum_{k=?}^{N_{p i l t h}} F_{P}(k) W_{P}(k)+W_{\text {dob }}-W_{B P}
$$

This alters the formulation of Eq. $(4-23)$ so that

$$
\begin{aligned}
B= & \sum_{k=2}^{N_{p a t h}} F_{p}(k)\left[\frac{P_{P_{0}}(k)-\sum_{P} \Delta P_{f, g}(k)}{\sum_{F} \frac{L}{A}(k)}\right]+\frac{P_{b o}-\sum_{d o b}^{\Delta P_{f, g}}}{\sum_{d o b} \frac{L}{A}} \\
E= & \sum_{k=2}^{N_{p a t h}} \frac{F_{P}(k)}{\sum_{P} P_{f, g}(k)}+\frac{1}{\sum_{\text {dob }} \frac{L}{A}} .
\end{aligned}
$$

The rest of $\mathrm{Eq} \cdot(4-23)$ remains the same.

\subsection{INTERMEDIATE SYSTEM}

The thermo-hydraulic modeling of the intermediate circuit is essentially unchanged from that in SSC-L, as reported earlier ${ }^{9}$.

The presence or likelihood of more than one intermediate heat exchanger operating in parallel for each intermediate loop has necessitated the inclusion of branching. Currently, the formulation does not allow for dissimilar branches. The flow through each IHX is then

$$
w_{2 X}=\frac{w_{I} n_{I}}{n_{X}}
$$

Similar branching was also built in earlier to allow for a user-specified 
number of superheaters and evaporators.

Another addition is the formulation of a model to represent spherical pump tanks. This has been necessitated by the presence of such a pump tank design in the Phenix secondary circuit.

\subsubsection{Spherical Pump Tank Model}

Fig. 16 shows the Phenix secondary pump including the tank. The inlet pressure to the pump, and hence, the base pressure in the intermediate circuit, depends on the level in the tank. This requires the level to be known at all times.

We can derive an expression relating the volume of sodium in the tank, $V_{\ell}$, and its operating level, $z_{\ell}$, as follows (see Fig. 17):

$$
d V=\pi\left(\frac{D}{2} \sin \right)^{2} d z
$$

The incremental height $d z$ can be written in terms of as

$$
d z=d\left(\frac{D}{2}-\frac{D}{2} \cos \right)
$$

Combining Eqs. (4-34), (4-35) and integrating yields

$$
\begin{aligned}
& v_{\ell}=\frac{\pi D^{3}}{8} \int_{0}^{\theta} \sin ^{3} \theta d \theta \\
& v_{\ell}=\frac{\pi D^{3}}{24}\left[\cos ^{3} \theta_{\ell}-3 \cos \theta_{\ell}+2\right]
\end{aligned}
$$

Equation (4-37) relates $V_{\ell}$ to the angle $\theta_{\ell}$, whereas the operating level is related to $\theta_{\ell}$ by

$$
z_{\ell}=\frac{D}{2}(1-\cos \ell)
$$




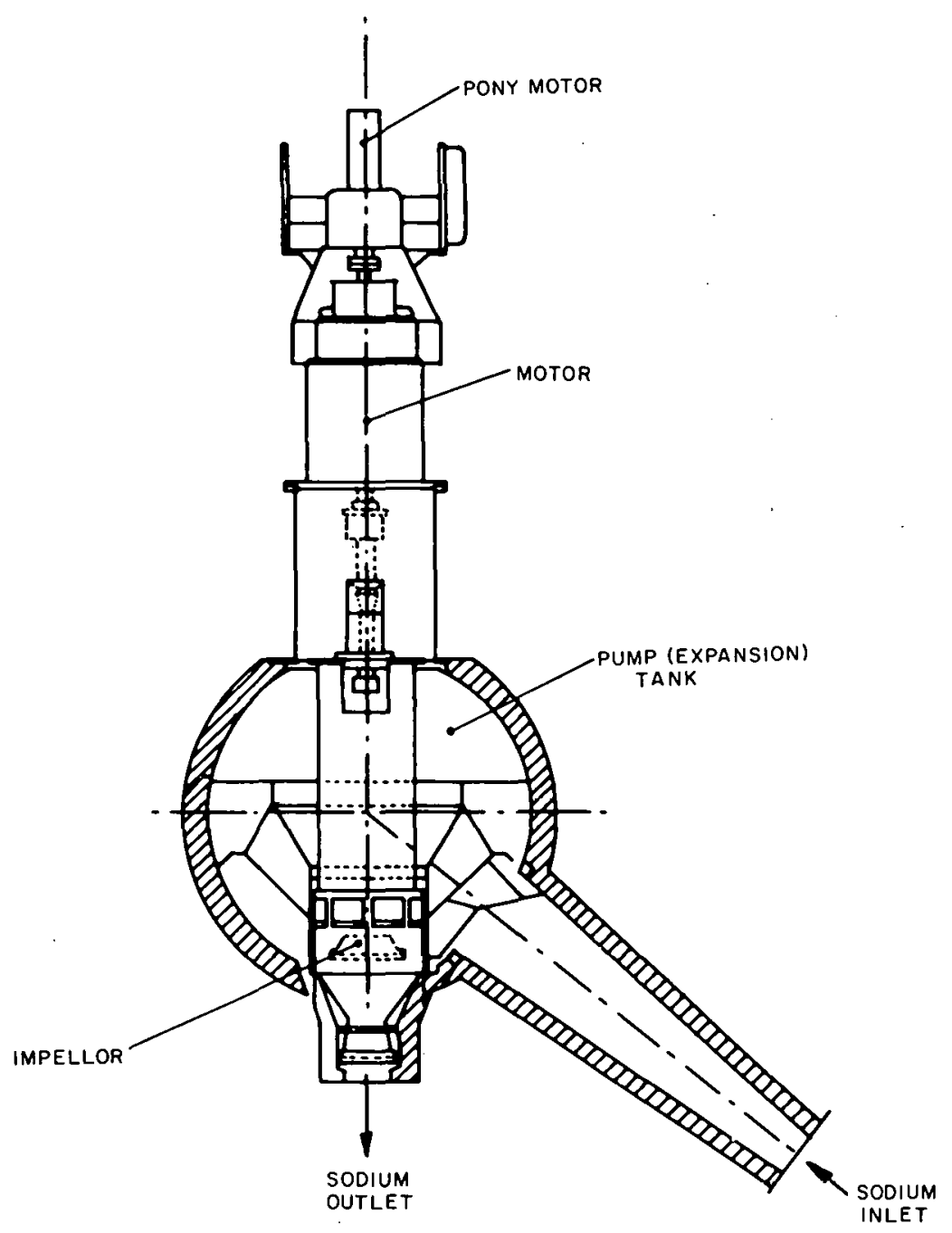

Figure 16. Phenix expansion tank and secondary pump

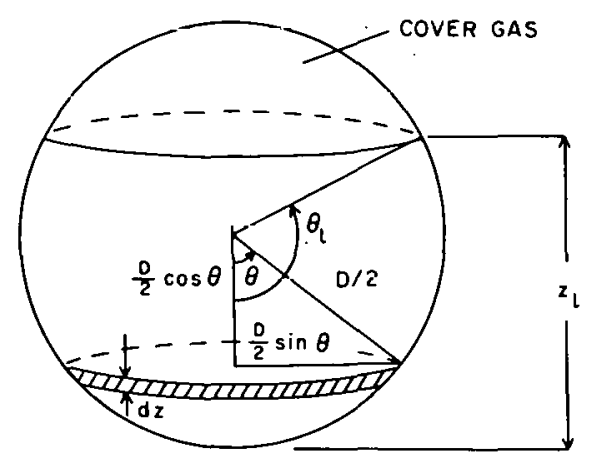

Figure 17. Model configuration for spherical expansion tank 
If $z_{\ell}$, the operating level is known during nominal, steady-state conditions, the angle $\theta_{\ell}$ can be evaluated from Eq. (4-38), and subsequently the volume of sodium obtained from Eq. (4-37).

During a transient, the level tracking is achieved as described below. The sodium volume in the tank is governed by the mass balance equation

$$
\frac{d}{d t}\left(\rho v_{\ell}\right)=w_{\text {in }}-w_{0}
$$

The integrated parameter here is $\rho V_{\ell}$ as opposed to $\rho z_{\ell}$ for the verti-

cal cylindrical tanks. To obtain $z_{\ell}$, we need first to solve Eq. (1-37) for $\theta_{\ell}$. Eq. (4-37) can be rearranged in the form

$$
\cos ^{3} \theta_{\ell}-3 \cos \theta_{\ell}+\left(2-\frac{24}{\pi D^{2}} v_{\ell}\right)=0
$$

This is a cubic equation in $\theta_{\ell}$, and has to be solved for its real roots.

\subsubsection{Solution of Cubic Equation}

Eq. (4.40) is in the normal form

$$
x^{3}+a x+b=0
$$

where $\quad x=\cos \theta_{\ell}$

$$
\begin{aligned}
& a=-3 \\
& b=2-\frac{24}{\pi D^{3}} V_{l}
\end{aligned}
$$

To apply the test for roots, we evaluate the expression

$$
\frac{b^{2}}{4}+\frac{a^{3}}{27}=-\frac{12 V_{\ell}}{\pi D^{3}}
$$

Since $V_{\ell}>0$, this means that

$$
\frac{b^{2}}{4}+\frac{a^{3}}{27}<0
$$


Eq. (4-40) therefore has three real and unequal roots given by ${ }^{15}$

$$
\cos \theta_{\ell, k}=2 \cos \left(\frac{\phi}{3}+120^{\circ} k\right) \quad k=0,1,2
$$

where $\phi$ is to be computed from

$$
\cos = \pm\left(1-\frac{12 V_{\ell}}{\pi D^{3}}\right)
$$

and where the upper sign is to be used if $b$ is positive and the lower sign if $b$ is negative.

With $\theta_{\ell}$ obtained as described above, Eq. (4-38) can be used to determine the transient level. The inlet pressure to the pump impeller is related to $z_{\ell}$ by

$$
P_{\text {Pin }}=P_{g}+\rho_{i n} g z_{\ell}
$$

\subsection{ENERGY BALANCE IN POOLS}

\subsubsection{Hot Pool Stratification}

Stable stratification occurs when hot, hence lighter fluid, forms a layer on top of cold fluid. This can occur in the hot pool region if the entering coolant is colder than the pool coolant and it experiences a large decrease in momentum. Since the hot pool forms a link in the primary flow circuit, it is necessary to predict the pool coolant temperature distribution with sufficient accuracy to determine its contribution to the net buoyancy head. It is also needed for the computation of the inlet temperature conditions for the components in the circuit.

During a normal reactor scram, the heat generation is reduced almost instantaneously while the coolant flow rate follows the pump coastdown. 
This mismatch between power and flow results in a situation. where the core flow entering the hot pool is at a lower temperature than the temperature of the bulk pool sodium. This temperature difference leads to stratification when the decaying coolant momentum is insufficient to overcome the negative buoyancy force. Instead of penetrating upwards, the cool, dense sodium is then deflected downward and outward in a stratified pattern.

Currently, the stratification of core flow in the hot pool is represented by a two-zone model, based on the model for mixing in the upper plenum of loop-type LMFBRs in SSC-L ${ }^{16}$. Accordingly, the hot pool is divided into two perfectly mixed zones, determined by the maximum penetration distance of the core flow. This distance, $7_{j}$, is related to the initiat Froude number, $F r_{0}$, of the average core exit flow. The temperature of each zone is computed from energy balance considerations. The temperature of the upper portion, $T_{A}$, will be relatively unchanged; in the lower region, however, $T_{B}$ will be changed and be somewhere between $T_{R o}$ and $T_{A}$ due to active mixing with the core exit flow as well as heat transfer with the upper zone. $T_{A}$ is mainly affected by interfacial heat transfer. The location of the interface will determine whether the upper region has any influence on the IHX inlet temperature. Full penetration is assumed for flow with positive buoyancy.

Further work on this aspect of the modeling is planned, and it is expected that the current representation of mixing will be improved with a two-dimensional, more rigorous treatment. The 1-D approach could then be retained as an option.

Compared to the upper plenum representation, the hot pool analys is is more complicatcd bccause the pool cross=sectional area is not. uniform. The volumes 
of the lower and upper zones, as well as their areas for heat transfer with the thermal barrier, have to be evaluated during the transient.

\subsubsection{Heat Transfer Areas}

The heat transfer area between the lower mixing zone $B$ and the barrier (see Fig. 18) is derived as follows:

$$
A_{b m 2}=\pi D_{1} z_{j} \quad \text { if } \quad z_{j}<z_{1}
$$

or

$$
A_{b m 2}=\pi D_{1} z_{1}+\frac{\pi}{4 \cos \theta}\left(D^{2}-D_{1}^{2}\right) \text { if } z_{1}<z_{j} \leq z_{2}
$$

where

or

$$
D=\frac{2\left(z_{j}-z_{1}\right)}{\tan \theta}+D_{1}
$$

$$
A_{b m 2}=\pi D_{1} z_{1}+\frac{\pi}{4 \cos \theta}\left(D_{2}^{2}-D_{1}^{2}\right)+\pi D_{2}\left(z_{j}-z_{2}\right) \text { if } z_{j}>z_{2}
$$

where

$$
z_{2}=z_{1}+\frac{\left(D_{2}-D_{1}\right)}{2} \tan \theta
$$

Here, $z_{1}, D_{1}, D_{2}$ and the angle of the redan, $\theta$, are user-input quantities. For a horizontal redan $\left(\theta=0^{\circ}\right), z_{2}=z_{1}$. For zone $A$, the area is evaluated from

$$
A_{a m 2}=A_{h m 2}-A_{b m 2}
$$

For the case of full penetration, $A_{b m 2}=A_{h m 2}$ and $A_{a m 2}=0$. 


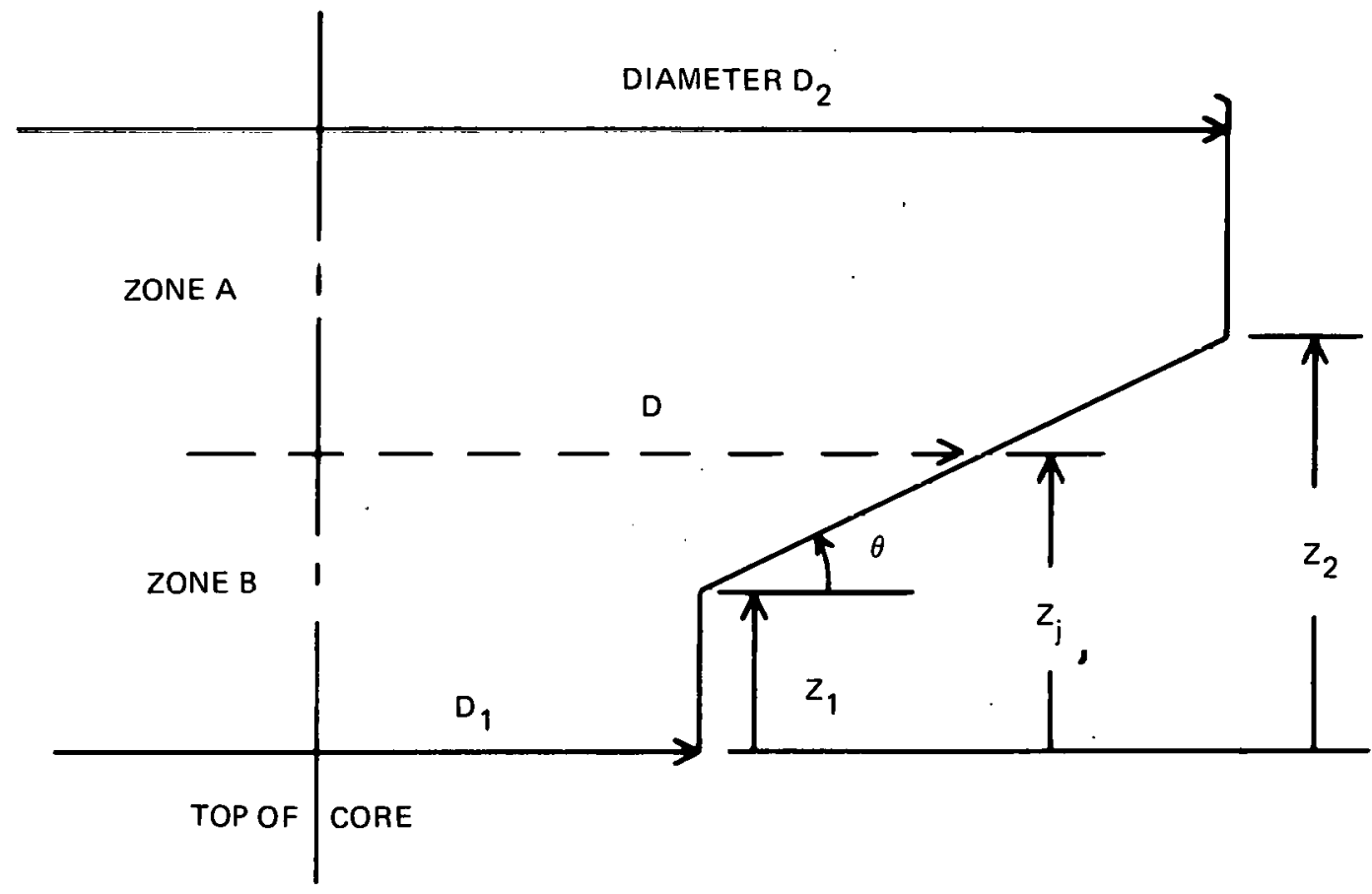

Figure 18. Configuration for calculation for heat transfer areas from the two zones to the barrier 


\subsubsection{Volumes of Zones}

The volume of sodium in zone B is given by

$$
v_{B}=\frac{\pi D_{1}^{2}}{4} z_{j} \quad \text { if } \quad z_{j}<z_{1}
$$

or

$$
V_{B}=\frac{\pi D_{1}^{2}}{4} z_{1}+\frac{\pi}{24} \tan \theta\left(D^{3}-D_{1}^{3}\right) \quad \text { if } z_{1}<z_{j} \leq z_{2}
$$

or

$V_{B}=\frac{\pi D_{1}^{2}}{4} z_{1}+\frac{\pi}{24} \tan \theta\left(D_{2}^{3}-D_{1}^{3}\right)+\frac{\pi D_{2}^{2}}{4}\left(z_{j}-z_{2}\right)$ if $z_{j}>z_{2}$

The volume of zone $A$ is then obtained from

$$
V_{A}=V_{H P}-V_{B}
$$

For the case of full penetration, i.e. $z_{j}=Z_{H P}-Z_{R o}, V_{B}=V_{H P}$ and $V_{A}=0$.

\subsubsection{Energy Equations}

The governing equations which determine the various temperatures in the hot pool are given below:

Lower mixing zone $B$ :

$$
\begin{aligned}
\rho_{B} V_{B} \frac{d e_{B}}{d t} & =W_{C}\left(e_{R o}-e_{B}\right)-(U A)_{b m 2}\left(T_{B}-T_{m 2}\right) \\
& -(U A)_{h m 1}(1-f)\left(T_{B}-T_{m 1}\right)-(h A)_{b a}\left(T_{B}-T_{A}\right) .
\end{aligned}
$$

Note that this equation includes mass conservation.

Upper mixing zone $A$ :

$$
\begin{aligned}
\rho_{A} V_{A} \frac{d e_{A}}{d t} & =\beta_{1} W_{C}\left(e_{B}-e_{A}\right)+(h A)_{b a}\left(T_{B}-T_{A}\right)-(U A)_{a m 2}\left(T_{A}-T_{m 2}\right) \\
& -(U A)_{h m 1} f\left(T_{A}-T_{m 1}\right)-(U A)_{h g}\left(T_{A}-T_{g}\right)
\end{aligned}
$$


Upper internal structure (metal $\mathrm{ml})$ :

$$
(M C)_{m 1} \frac{d T_{m 1}}{d t}=(U A)_{h m 1}\left[f T_{A}+(1-f) T_{B}-T_{m 1}\right]-(U A)_{g m 1}\left(T_{m 1}-T_{g}\right)
$$

Barrier (metal m2):

$$
(M C)_{m 2} \frac{d T_{m 2}}{d t}=(U A)_{h m 2}\left[\frac{A_{a m 2} T_{A}+A_{b m 2} T_{B}}{A_{h m 2}}-T_{m 2}\right]-(U A)_{c m 2}\left(T_{m 2}-T_{C P}\right)(4-56)
$$

Based on sensitivity analysis, $U_{h m 2}$ is not very sensitive to changes in sodium, temperature, and so this equation is derived assuming $U_{\mathrm{bm} 2}=U_{\mathrm{am} 2}$.

Roof (metal m3):

$$
(M C)_{m 3} \frac{d T_{m 3}}{d t}=(U A)_{g m 3}\left(T_{g}-T_{m 3}\right)
$$

In this equation, the heat transfer from the roof to the outside ambient has been neglected.

Cover gas:

$$
\text { (MC) } \begin{aligned}
\frac{d T_{g}}{d t} & =(U A)_{h g}\left(T_{A}-T_{g}\right)-(U A)_{c g}\left(T_{g}-T_{C P}\right) \\
& +(U A)_{g m 1}\left(T_{m 1}-T_{g}\right)-(U A)_{g m 3}\left(T_{g}-T_{m 3}\right)
\end{aligned}
$$

The auxiliary equations required by the above governing equations are

$$
\begin{gathered}
A_{b a}=\pi D^{2} / 4 \\
f=1-z_{j}(t) /\left(Z_{H P}(t)-z_{R_{0}}\right)
\end{gathered}
$$

Liquid sodium densities $\rho_{A}$, $\rho_{B}$, etc. are nhtained from the constitutive relationship $\rho=\rho(T)$, where the sodium temperature, $T$, is related to its enthalpy by $T=T(e)$. 
The heat transfer areas $A_{h m l}, A_{g m l}, A_{c g}, A_{h g}$ and $A_{g m 3}$ are user-input quantities. $A_{b m 2}, A_{a m 2}$ are calculated as described earlier. The control index $B_{1}$ represents the location of the jet penetration relative to the heat exchanger inlet. Thus,

$$
\begin{aligned}
& \text { and exin } \left.=e_{B}\right\} \quad \text { for } z_{j} \geq\left(z_{x_{i n}}-z_{R_{0}}\right)
\end{aligned}
$$

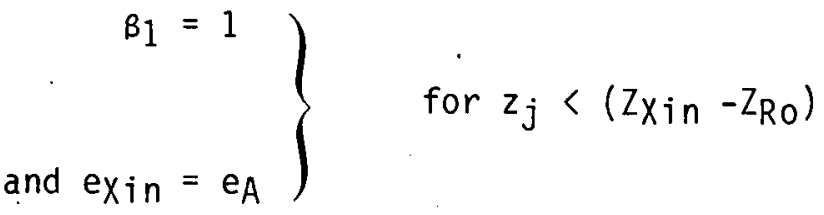

$z_{j}$ is defined as ${ }^{17}$

$$
z_{j}=\left(1.0484 F r_{0}^{0.785}\right) r_{0}+z_{c h}
$$

where $\mathrm{Fr}_{0}$ is the discharge Froude number, defined as

$$
F r_{0}=\left(\frac{W_{C}}{\pi r_{0}{ }^{2} \rho_{R o}}\right)^{2} \quad\left[\frac{\rho_{B}}{g r_{0}\left(\rho_{R O}-\rho_{B}\right)}\right]
$$

For full penetration $(f=0.0)$, the equation for zone $B$ is replaced by:

$$
\begin{aligned}
\rho_{B} V_{B} \frac{d e_{B}}{d t} & =W_{C}\left(e_{R o}-e_{B}\right)-(U A)_{b m 2}\left(T_{B}-T_{m 2}\right) \\
& -(U A)_{h m 1}\left(T_{B}-T_{m 1}\right)-(U A)_{h g}\left(T_{B}-T_{g}\right)
\end{aligned}
$$

and

$$
\frac{\mathrm{de}_{A}}{\mathrm{dt}}=\frac{\mathrm{de}_{B}}{\mathrm{dt}}
$$


For no penetration $(f=1.0)$, the equation for zone $A$ is replaced by

$$
\begin{aligned}
\rho_{A} V_{A} \frac{d e_{A}}{d t} & =W_{C}\left(e_{R o}-e_{A}\right)-(U A)_{a m 2}\left(T_{A}-T_{m 2}\right) \\
& -(U A)_{h m 1}\left(T_{A}-T_{m 1}\right)-(U A)_{h g}\left(T_{A}-T_{g}\right)
\end{aligned}
$$

and

$$
\frac{d e_{B}}{d t}=\frac{d e_{A}}{d t}
$$

\subsubsection{Cold Pool}

Currently, we assume perfect mixing of the IHX flow with the cold pool sodium, but allow for a user-specified fraction $B X$ of the flow to go directly to the adjacent pumps. Based on this, the energy equation is derived as

$$
\begin{aligned}
(\rho V)_{C P} \frac{d e_{C P}}{d t} & =\left(1-\beta_{X}\right) w_{X \text { tot }}\left(e_{X o}-e_{C P}\right)+W_{B P}\left(e_{B P}-e_{C P}\right) \\
& +(U A)_{C m 2}\left(T_{m 2}-T_{C P}\right)+(U A)_{C G}\left(T_{\text {ga }}-T_{C P}\right)-(U A)_{C m 4}\left(T_{C P}-T_{m 4}\right)
\end{aligned}
$$

Also, due to the possibility of shortcircuiting, the enthalpy of fluid entering the pumps is not necessarily equal to the enthalpy of the cold pool sodium. Rather, it is given by the expression:

$$
e_{\text {Pin }}=\frac{w_{\text {tot }} e_{C P}+\beta_{X} w_{X \text { tot }}\left(e_{X_{0}}-e_{C P}\right)}{W_{\text {Ptot }}}
$$

For $\beta_{X}=0$, this reduces to

$$
\text { epin }=e_{C P}
$$

Lower structurés (metal $\mathrm{m4}$ ):

$$
(M C)_{m 4} \frac{d T_{m 4}}{d t}=(U A)_{c m 4}\left(T_{C P}-T_{m 4}\right)
$$


The mass heat capacities of all structures ( $\mathrm{ml}$ to $\mathrm{m4}$ ), as well as the heat capacity of cover gas, mass of sodium in hot and cold pools, areas for heat transfer, are needed for transient calculations.

The total volume of sodium in the hot pool is calculated during steady state from:

$$
V_{H P}=\frac{\pi D_{1}^{2}}{4} z_{1}+\frac{\pi}{24} \tan \theta\left(D_{2}^{3}-D_{1}^{3}\right)+\frac{\pi D_{2}^{2}}{4}\left(z_{H P}-Z_{R o}-z_{2}\right)
$$

and during transients from

$$
v_{H P}^{\text {new }}=V_{H P}^{\text {old }}+A_{\text {hg }}\left(Z_{H P}^{\text {new }}-Z_{H P}^{\text {old }}\right)
$$

The volume of cold pool sodium during steady-state is obtained from

$$
v_{C P}=\frac{m_{\text {tot }}-(\rho V)_{H P}}{\rho_{C}}
$$

During transients, it is obtained from

$$
v_{C P}{ }^{\text {new }}=v_{C P}{ }^{\text {old }}+A_{C g}\left(Z_{C P}^{\text {new }}-Z_{C P}{ }^{\text {old }}\right)
$$

In the energy equations presented above, axial heat conduction through the walls is neglected. For example, in the $T_{m 3}$ equation, the effect of including axial conduction in the tank wall on $T_{m 3}$ is less than $1 K$. Its effect on system temperatures was even less.

\subsection{INTERMEDIATE HEAT EXCHANGER}

The intermediate heat exchanger in pool-type LMFBRs is identical in function, and very similar in design, to that in loop-type designs. The only difference arises from the different configuration in the primary system, where 
the IHX draws coolant from an open pool (in the hot pool concept) and discharges to another open pool. The liquid levels in the hot and cold pools reflect the hydraulic flow resistance through the IHXs. The liquid-level difference in Phenix, for example, is $66 \mathrm{~cm}$. under normal operation. In PFR, the difference is somewhat higher. In both cases, however, the differential level is low. This of course, requires the IHX to have a low pressure drop on the primary side. The main concern with a low-pressure-drop heat exchanger is its effect on flow distribution. Poor flow distribution can adversely affect operational reliability by causing temperature distributions and resultant thermal stresses that could exceed design allowances.

In most IHX designs, the primary coolant flows in the shell side, while the secondary coolant flows in the tubes. However, for pool-type designs, particularly the hot pool concept, where the pressure losses in the primary side are limited as discussed above, it may be advantageous to send primary flow through the tubes to ensure good flow distribution. PFR is an example of this design choice. The problem of flow distribution is then transferred to the secońdary side of the unit. Since high pressure drops can be more readily accommodated by the secondary system, flow baffles such as the disc-and-donut type could be considered to improve the flow distribution.

The IHX model, therefore, has to be extended to allow primary flow in the tubes.

\subsubsection{Pressure Losses}

Figure 19 shows the IHX flow profile. Primary coolant flows downward in the active heat transfer region and exits at the bottom of the unit. The secondary coolant flows down the central downcomer into the bottom header 


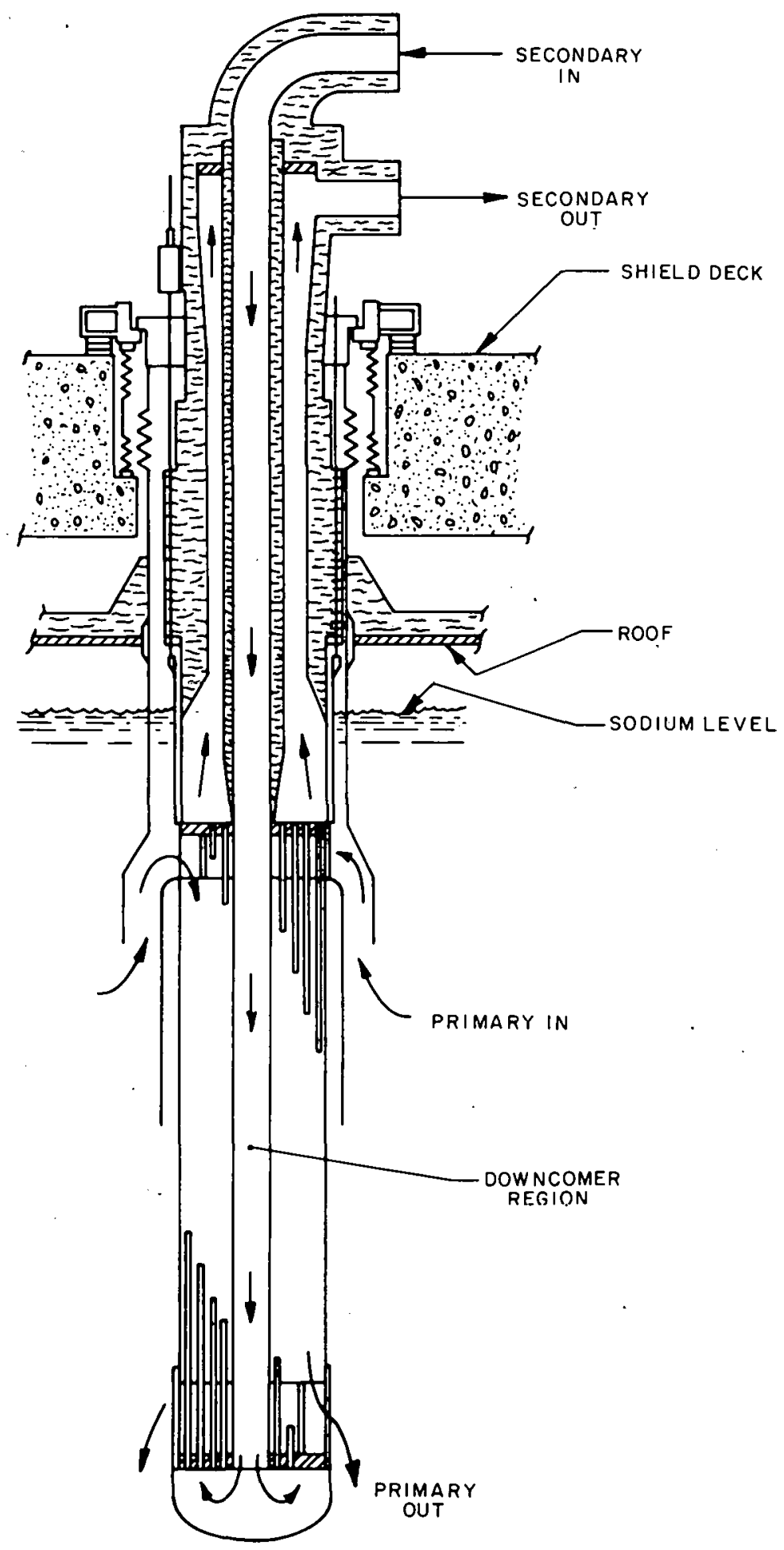

Figure 19. Profile of intermediate heat exchanger 
(inlet plemum region) where it turns upward to present a counterflow arrangement in the heat transfer region. In all cases, the primary flow is downward, and this helps to simplify the formulation.

The pressure losses can be expressed as described in Section 3.3.1. For the primary side, this gives

$$
\begin{aligned}
\left(\Delta P_{f, g}\right)_{1 X} & =\frac{W_{1 x^{2}}}{A_{p}{ }^{2}}\left(\frac{1}{\rho_{N}}-\frac{1}{\rho_{l}}\right)+\frac{1}{2} \frac{W_{1 x}\left|W_{1 x}\right|}{D_{p} A_{p}{ }^{2}} \int_{0}^{L} \frac{f}{\rho} d x+\Delta P_{g} \\
& + \text { inlet loss + exit loss }+k_{1 x} \frac{W_{1 x}\left|W_{1 x}\right|}{\overline{\rho A}{ }_{p}{ }^{2}}
\end{aligned}
$$

And, for the secondary side,

$$
\begin{aligned}
\left(\Delta P_{f, g}\right)_{2 \cdot X} & =\frac{W_{2 X^{2}}}{A_{S}{ }^{2}}\left(\frac{1}{\rho_{1}}-\frac{1}{\rho_{N}}\right)+\frac{1}{2} \frac{W_{2 X}\left|W_{2 X}\right|}{D_{s} A_{s}{ }^{2}} \int_{0}^{L} \frac{f}{\rho} d x+\Delta P_{g} \\
& + \text { in1et 10ss + exit loss }+k_{2 X} \frac{W_{2 X}\left|W_{2 X}\right|}{\overline{\rho A}{ }_{s}{ }^{2}}
\end{aligned}
$$

In Eqs. $(4-76),(4-77)$, the primary flow area $A_{p}$, hydraulic diameter $D_{p}$, secondary flow area $A_{S}$, and hydraulic Diameter $D_{S}$ are defined for shellside primary flnw as follows:

$$
\begin{aligned}
& A_{p}=n_{t} \frac{\pi D_{2}^{2}}{4}\left[\frac{2 \sqrt{3}}{\pi}\left(\frac{p}{D_{2}}\right)^{2}-1\right] \\
& D_{p}=\frac{4 A_{p}}{n_{t} \pi D_{2}} \\
& A_{S}=D_{l} \frac{\pi D_{1}}{4} \\
& D_{S}=D_{1}
\end{aligned}
$$


where $D_{1}, D_{2}$ are the inner and outer diameter of the tubes respectively. To extend the model for primary flow through the tubes, these parameters need to be re-specified as follows:

$$
\begin{aligned}
& A_{p}=n_{t} \frac{\pi D_{1}^{2}}{4} \\
& D_{p}=D_{1} \\
& A_{s}=n_{t} \frac{\pi D_{2}^{2}}{4}\left[\frac{2 \sqrt{3}}{\pi}\left(\frac{P}{D_{2}}\right)^{2}-1\right] \\
& D_{s}=D_{1}
\end{aligned}
$$

The pitch-to-diameter ratio, $\frac{P}{D_{2}}$, is taken to be the average value in case the pitch is not uniform throughout the tube bundle. Contraction and expansion losses occurring at the entrance and exit regions of the tube bundle can be lumped into the 'uncertainty absorber' loss coefficient.

\subsubsection{Heat Transfer}

The model is essentially unchanged from SSC-L. The energy equations are written using nodal heat balance with the 'donor cell' differencing approach. The slight modifications are extensions to allow tube-side primary flow. The equations in the active heat transfer region are:

\section{Primary coolant}

$$
\begin{aligned}
\rho V_{p} \frac{d}{d t}\left(e_{p_{i+1}}\right) & =W_{1 x}\left(e_{p_{i}}-e_{p_{i+1}}\right)-U_{p t} A_{p t}\left(T_{p_{i j+1}}-T_{t_{i}}\right) \\
& -k U_{p s h} A_{p s h}\left(T_{p_{i j+1}}-T_{s h_{i}}\right), i=1, N
\end{aligned}
$$




\section{Secondary coolant}

$$
\begin{aligned}
\rho V_{s} \frac{d}{d t}\left(e_{s_{i}}\right) & =w_{2} x\left(e_{s_{i+1}}-e_{s_{i}}\right)+U_{s t}{ }^{A} s t\left(T_{t_{i}}-T_{s_{i j+1}}\right) \\
& -(1-k) U_{s s h}{ }_{s s h}\left(T_{s_{i j+1}}-T_{s h_{i}}\right), i=1, N
\end{aligned}
$$

Tube wall

$$
\begin{array}{r}
M_{t} c_{t} \frac{d}{d t}\left(T_{t}\right)=U_{p t} A_{p t}\left(T_{p_{i j+1}}-T_{t_{i}}\right)-U_{s t} A_{s t}\left(T_{t_{i}}-T_{s_{i i+1}}\right) \\
i=1, N-1
\end{array}
$$

\section{Shell wall}

$M_{s h} C_{s h_{i}} \frac{d}{d t}\left(T_{s h_{i}}\right)=k U_{p s h} A_{p s h}\left(T_{p_{i j+1}}-T_{s h_{i}}\right)+(1-k) U_{s s h} A_{s s h}\left(T_{s i j+1}-T_{s h_{i}}\right)$

In the above equations, $k=1$ for shell-side primary flow, and 0 for tube-side primary flow. $v_{p}, V_{s}$ are the control volumes between $i$ and $i+1$ on primary and secondary sides, respectively. $U_{p t}, U_{s t}, U_{p s h}, U_{s s h}$ denote the overall heat transfer coefficients and $A_{p t}, A_{s t}, A_{p s h}$ and $A_{s s h}$ are the heat transfer areas per length $\Delta x$.

The heat-transfer areas are defined as

$$
\begin{aligned}
& A_{p t}=k \pi D_{2} n_{t} \Delta x=(1-k) \pi D_{1} n_{t} \Delta x \\
& A_{s t .}=k \pi D_{1} n_{t} \Delta x=(1-k) \pi D_{2} n_{t} \Delta x \\
& A_{s s h}, A_{p s h}=\frac{A_{s h}}{L} \Delta x
\end{aligned}
$$


where $n_{t}=$ number of active heat transfer tubes, $A_{s h}$ is the shell heat transfer area, and $L$ is the length of the active heat transfer region.

The overall heat transfer coefficients are defined, based on the resistance concept, by:

$$
\begin{gathered}
\frac{1}{U_{p t}}=\frac{1}{h_{f i l m, p}}+r_{\text {wall }, p}+\frac{1}{h_{\text {foul }, p}} \\
\frac{1}{U_{s t}}=\frac{1}{h_{f i l m, s}}+r_{\text {wall }, s}+\frac{1}{h_{\text {foul }, s}} \\
\frac{1}{U_{p s h}}=\frac{1}{h_{f i l m, p}} \\
\frac{1}{U_{s s h}}=\frac{1}{h_{f i l m, s}}
\end{gathered}
$$

where the film coefficients are calculated in terms of $\mathrm{Nu}$ by

$$
h_{f i l m, p}=\frac{N u_{p t} k_{p}}{D_{p}}
$$

and

$$
n_{f i l m, s}=\frac{N u_{s t} k_{s}}{D_{s}}
$$

$D_{p}, D_{s}$ have been defined in the previous subsection. The Nusselt numbers, $\mathrm{Nu}_{\mathrm{pt}}$ and $\mathrm{Nu}_{s t}$, are obtained from established correlations.

The wall resistance terms are obtained by dividing the tube wall thickness equally between primary and secondary sides, since $T_{t}$ is defined at the midpoint of wall thickness.

If

$$
r_{A}=\frac{D_{2}}{2} \quad \frac{\ln \left(\frac{2 D_{2}}{D_{1}+D_{2}}\right)}{k_{t}}
$$


and

Then,

$$
r_{B}=\frac{D_{1}}{2} \quad \frac{\ln \left(\frac{D_{1}+D_{2}}{2 D_{1}}\right)}{k_{t}}
$$

$$
r_{\text {wall, }}=k r_{A}+(1-k) r_{B}
$$

and

$$
r_{\text {wall,s }}=k r_{B}+(1-k) r_{A}
$$

where $k=1$ for shell-side primary flow.

Equations (4-80) to (4-83), along with the plena equations, are integrated by a fully implicit simple-layer scheme. The heat flux terms in Eqs. (4-80), (4-81) are allowed to be determined explicity, thereby uncoupling them. These equations are then solved in a marching fashion without resorting to matrix inversions.

The energy equations for the piping are written and solved in the same manner. For details of the piping model, the interested reader is referred to Ref. 18.

\subsection{SOLUTION PROCEDURE}

During a transient the system hydraulic equations and equations for energy balance within the primary tank are solved together by a fifth-order predictor-corrector scheme. The solution procedure is shown in Figs. 20-22 by means of simple flow charts. Only the main calculations which are involved during each timestep are indicated. Details of the algorithm are not shown as they can be found elsewhere ${ }^{19}$.

The thermal equations for the IHX and pipings (both primary and intermediate systems), are solved in a marching fashion in the direction of 


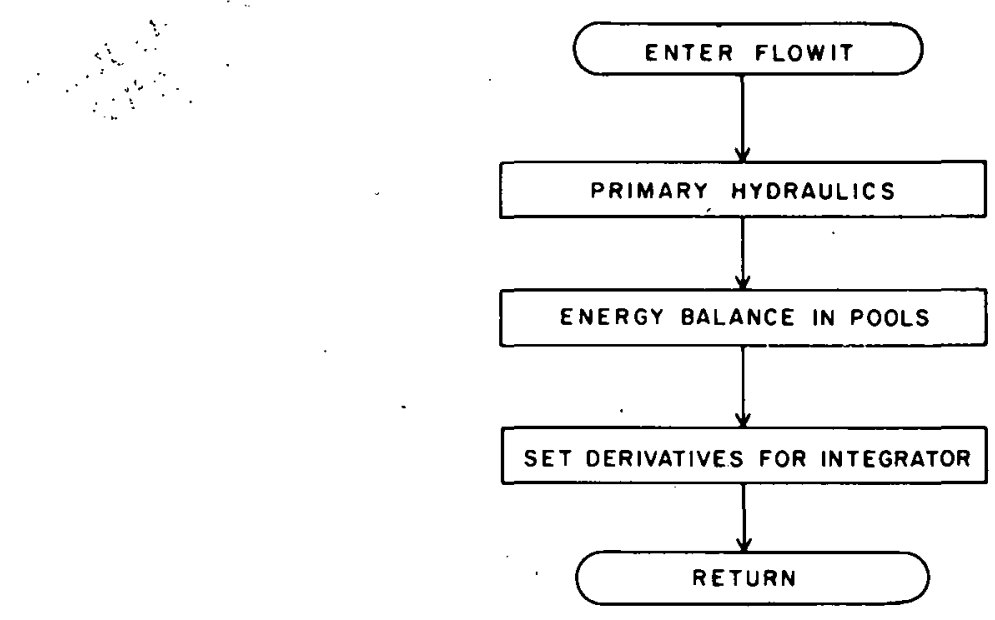

Figure 20. Driver for transient thermal-hydraulic calculations in primary system 


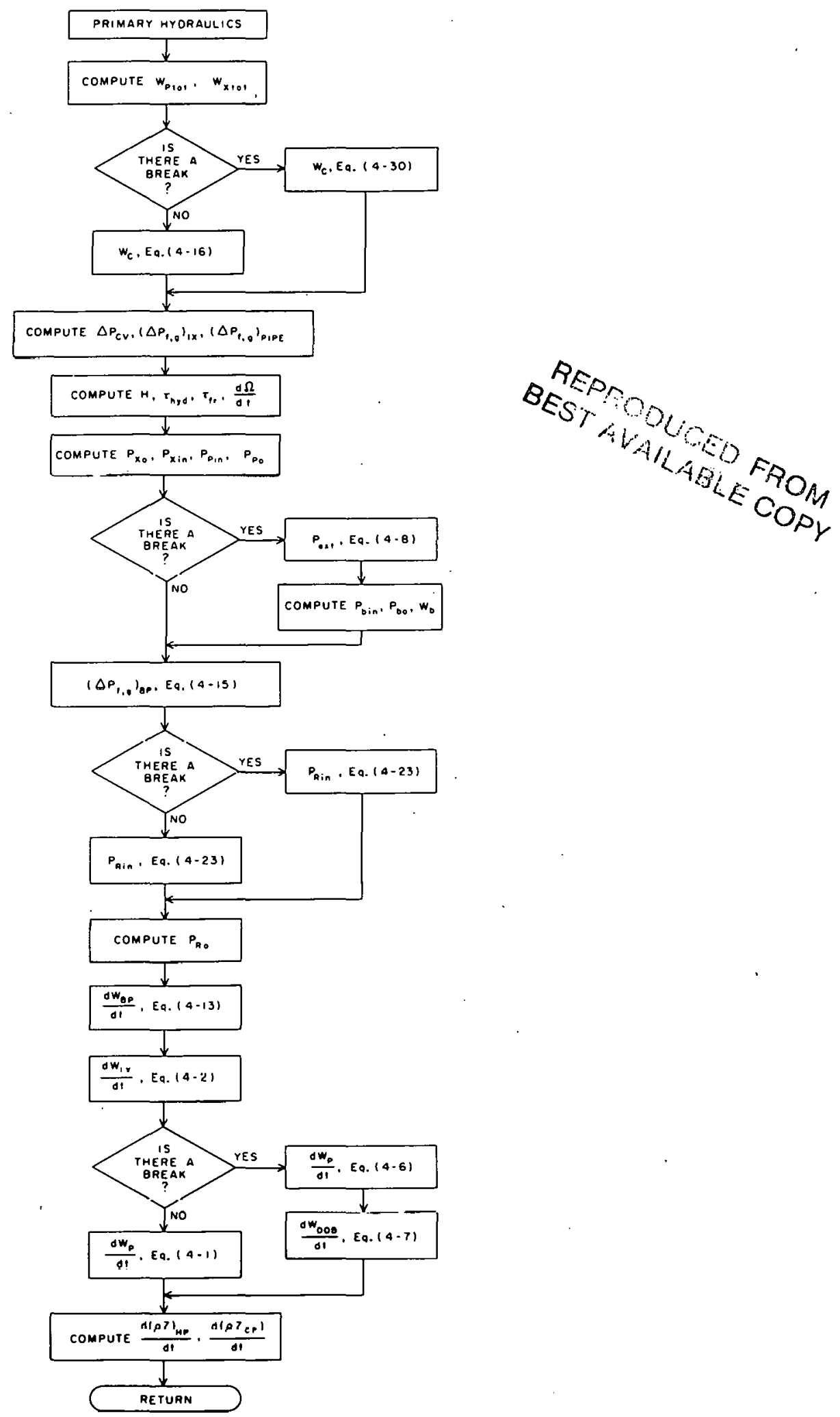

Figure 21. Calculational logic for primary hydraulics 


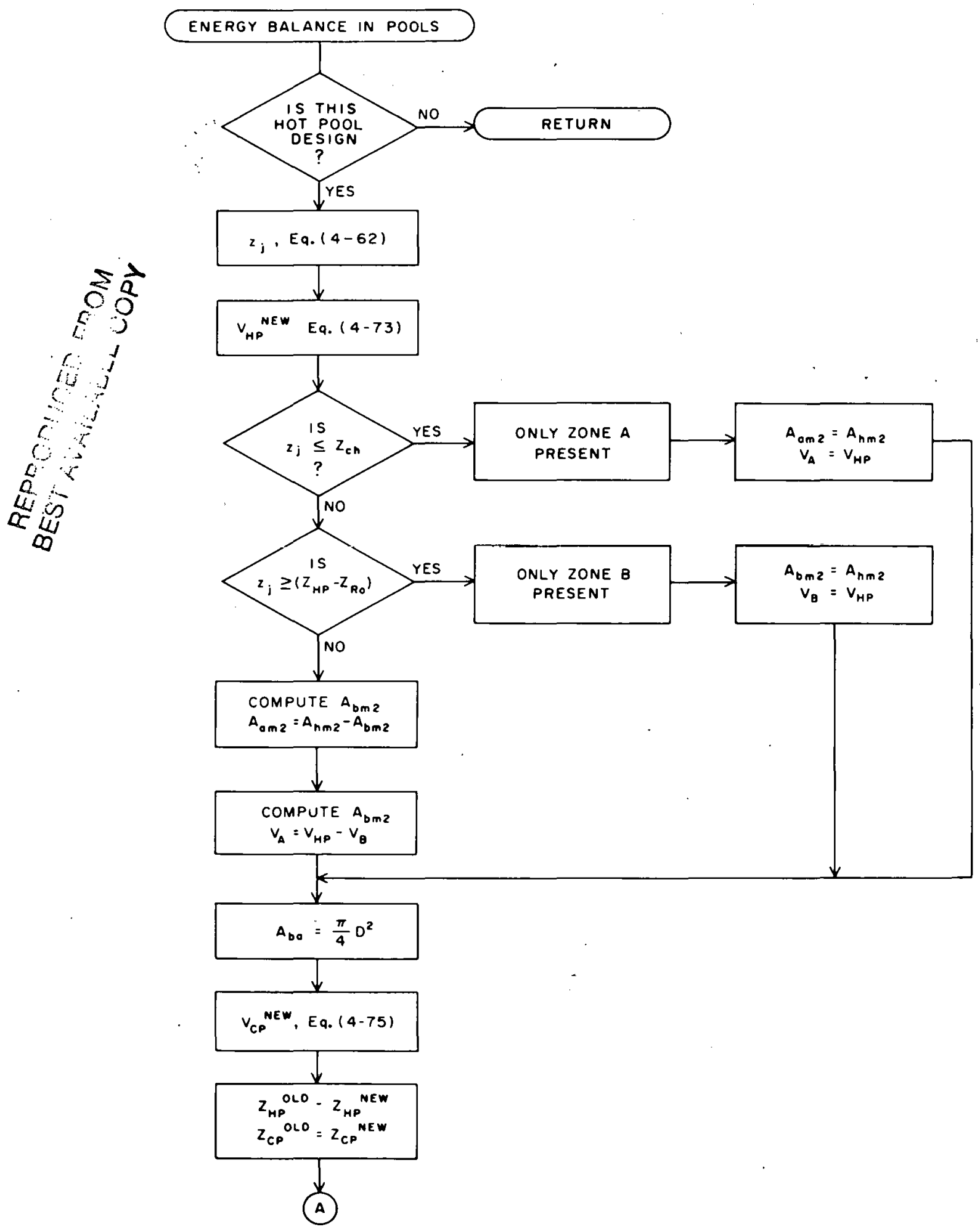

Figure 22. Calculational logic for energy balance within primary tank 


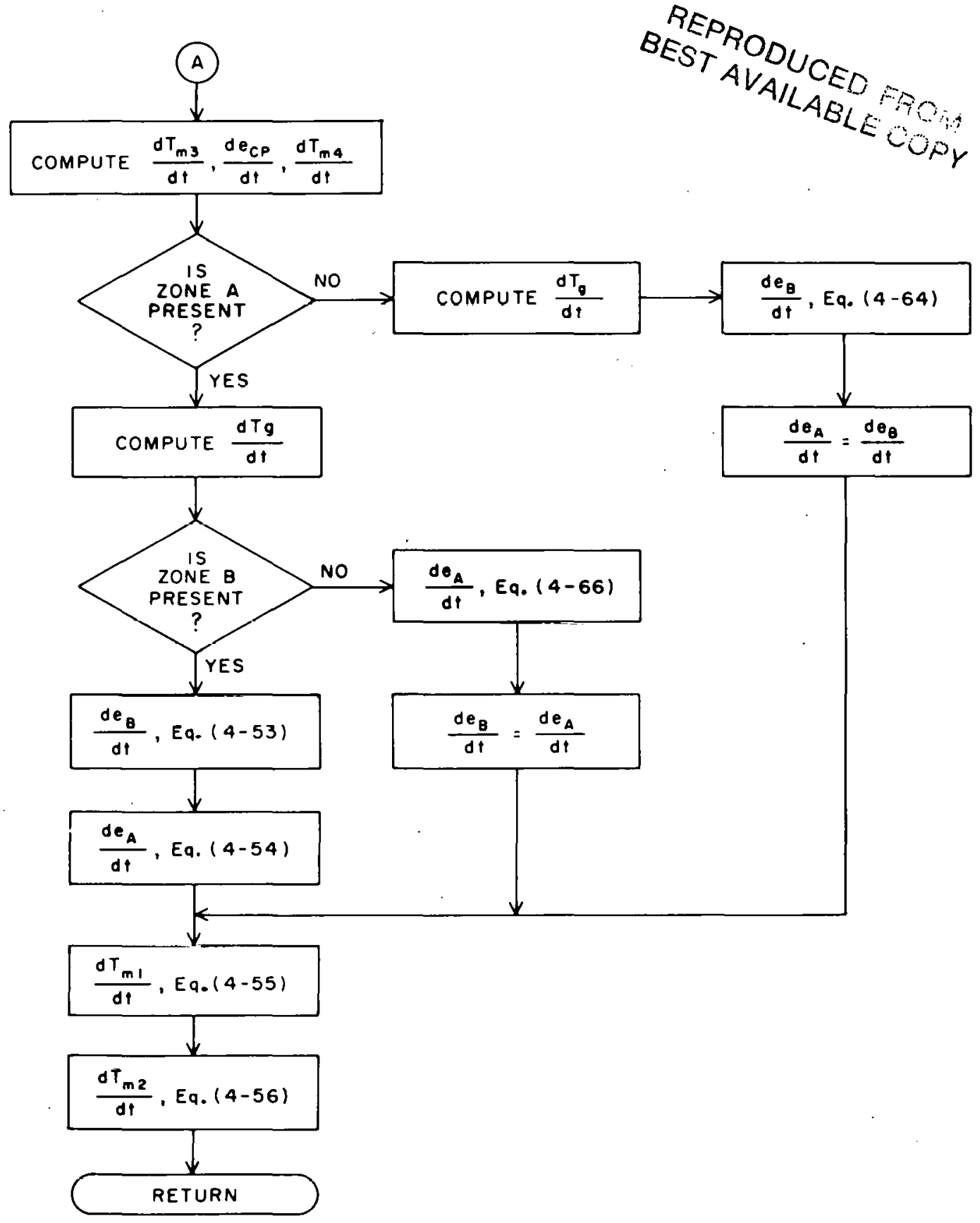

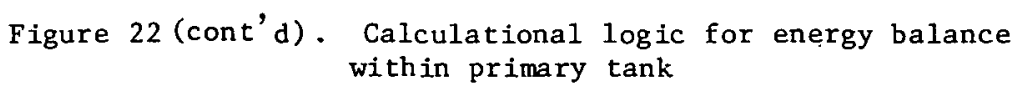


GENERAL FLOWCHARTS

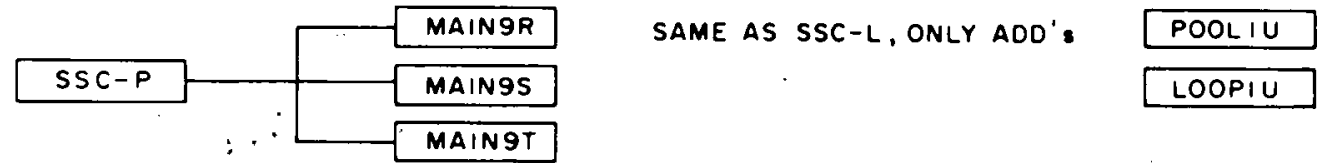

Figure 23. Three main driver programs of SSC-P

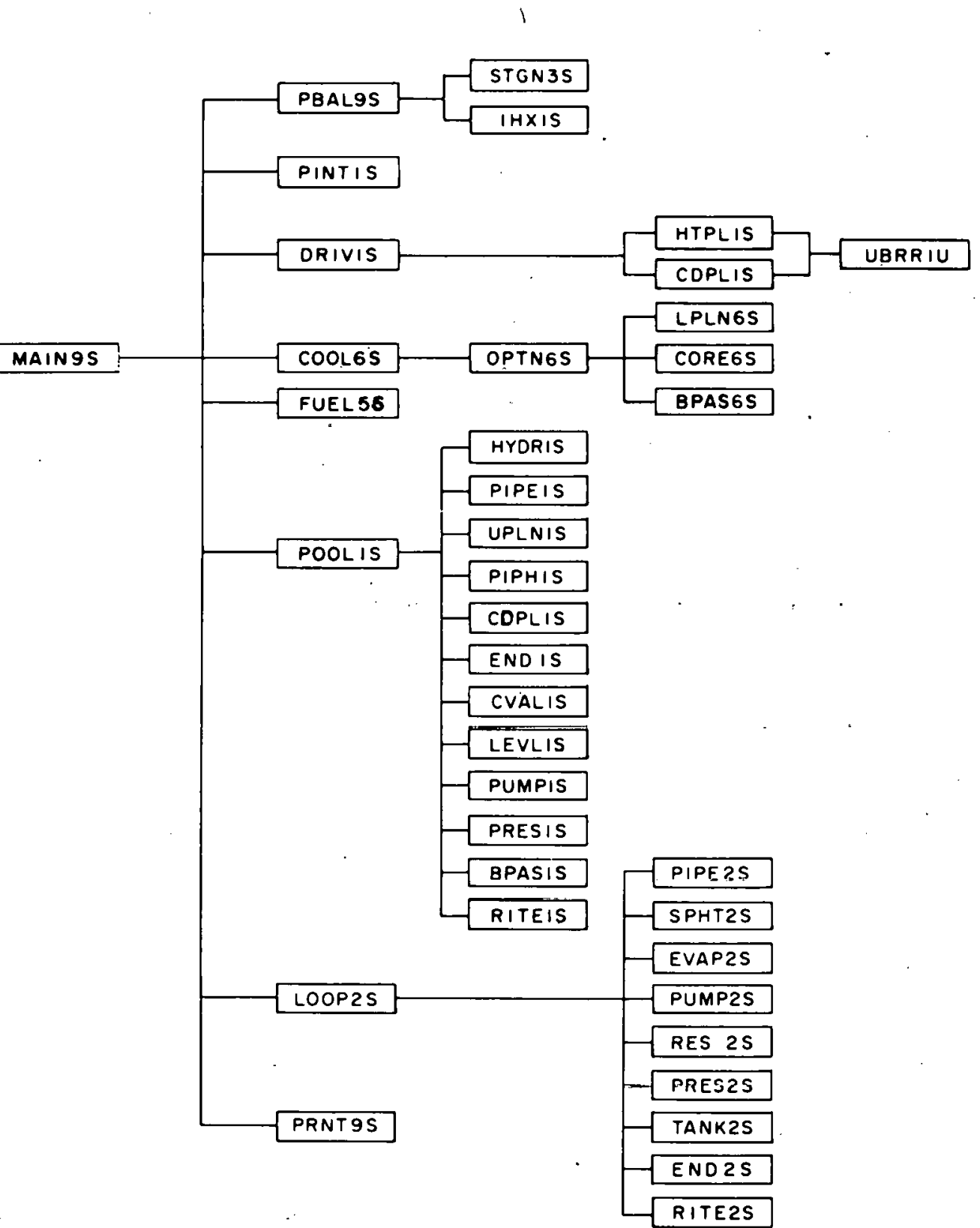

Figure 24. MAIN9S flow diagram 


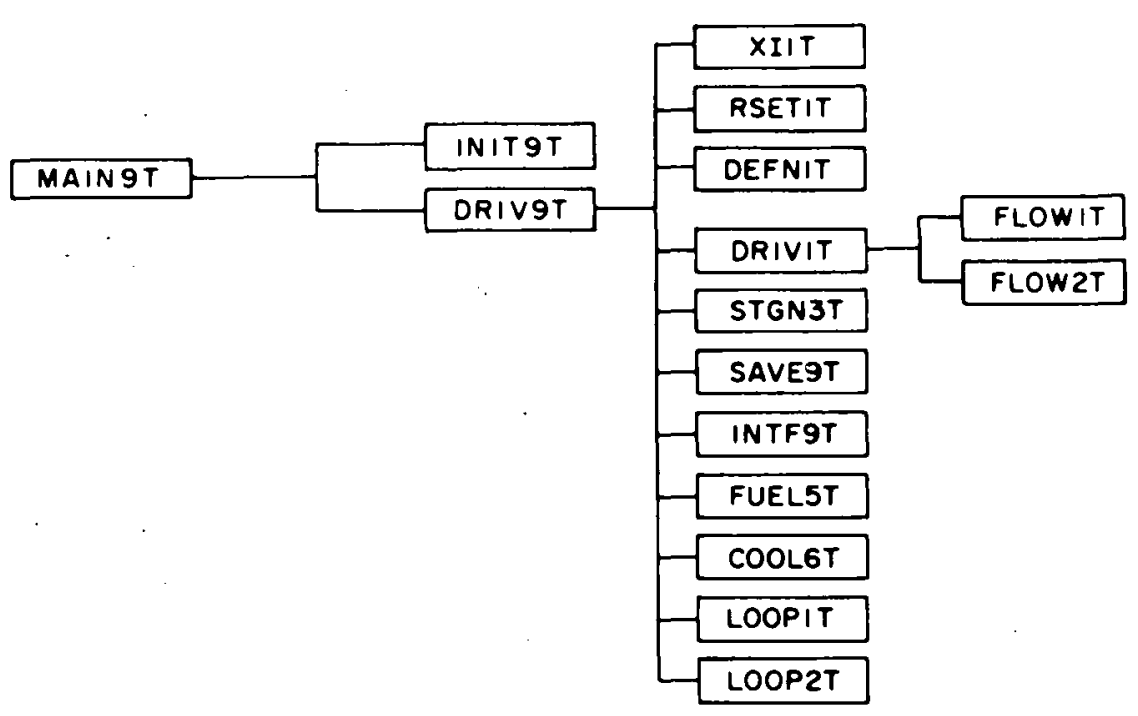

Figure 25. MAIN9T flow diagram

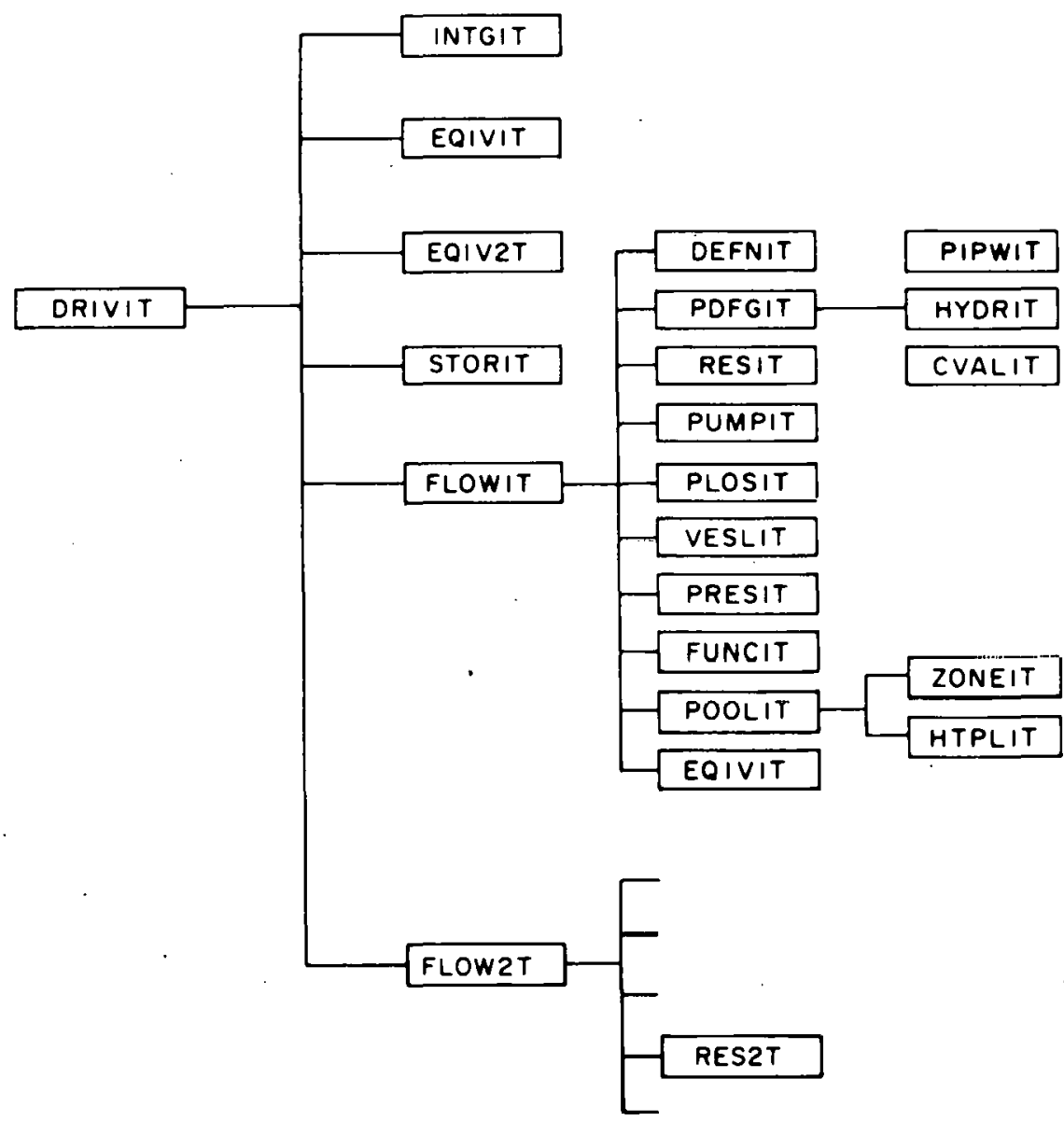

Figure 26. DRIVIT flow diagram 
flow. Since the IHX and pipings are highly nodalized, the number of thermal equations to be solved is too large to be handled by the predictor-corrector algorithm.

The combined solution is made possible by judiciously taking advantage of the properties of the flowing medium. Thus, in the liquid sodium circuits, the time-dependent energy and momentum equations can be decoupled since the effect of pressure on subcooled liquid sodium properties is considered negligible. The energy equations have only a weak influence on the momentum equations through the sodium properties. This allows the hydraulic equations (along with the energy balance equations in the primary tank) to be solved first, using coolant properties from the IHX and pipe as boundary conditions, evaluated at the previous timestep. The component energy equations can then be readily solved, using the most recent flow value.

More details on the numerical technique employed in SSC can be found in Ref. 9 .

\subsection{SOME CONSIDERATIONS FOR COLD POOL CONCEPT}

In a generic cold pool concept (see Fig. 2), there is also a hot leg pipe connecting the reactor outlet plenum with the IHX inlet. Since a substantial temperature gradient, equal to the difference between reactor outlet and inlet temperatures, exists between the hot sodium in the pipe and cold pool sodium, the pipe wall must be insulated. To protect the insulation from corrosion in a sodium environment, it could be imbedded within the wall.

Pool-type systems have an enormous inventory of sodium within the primary tank. The heat capacity of the sodium inventory is available to absorb heat following a postulated loss of IHX cooling. In this respect, the cold pool 
concept has a larger margin, since its bulk sodium is at reactor inlet temperature. Further, for the cold pool concept, any leakage from a reactor outlet pipe to the bulk sodium of the pool would only heat up the pool. Since the pool has such enormous thermal capacity, safety would not be compromised.

The presence of a hot-leg pipe, and the absence of a free liquid level in the outlet plenum, will somewhat modify the formulation for primary system coolant dynamics. This is briefly summarized below. Some considerations for the energy balance calculations have been briefly mentioned with reference to the flow chart of Fig. 15.

Since the reactor outlet plenum is pressurized with no free surface, the flow rate in the $I H X$ will be related to the pump flow rate by means of a simple algebraic relation. As a result, during a transient, the inventory of sodium in the cold pool remains constant, and its volume, hence level can only change due to thermal expansion effects (i.e., coolant density changes with temperature, hence time).

For an intact system, the reactor inlet pressure is obtained in much the same way as for the hot pool concept, by applying mass conservation at the reactor inlet, and then relating the derivatives of flow through the pump and reactor. It would also be given by $\mathrm{Eq} \cdot(4-23)$. The difference is that, due to the absence of a free liquid level, $P_{R_{0}}$ in Eq. (4-23) is not known and lids lu be determined. Assuming that $P_{\text {Ro }}$ is at the same elevation as the reactor outlet pipe, an expression can be derived for $P_{R o}$ in terms of $P_{R i n}$ and flow losses, by applying mass conservaton at the reactor outlet and then relating the flow deriviatives through the core and IHX. The simultaneous solutions of the two equations would then yield $P_{R i n}$ and $P_{R o}$. The rest of 
the formulation for coolant dynamics remains unchanged from the hot pool concept.

To simulate the transient following a primary pipe rupture accident event, the formulation should also allow for a break in the hot leg pipe. 


\section{INPUT DATA PREPARATION}

The first intended application of the SSC-P code is to analyze, in detail, any one or more of the independent EPRI sponsored design studies of a 1000 MWe pool-type LMFBR. Perhaps the first design selected for this purpose will be

the conceptual study performed by the GE-Bechtel team ${ }^{2}$. However, the code development effort to date has been guided primarily by the Phenix design and, as such, it would be helpful if this could lead to some trend comparisons. Towards this end, the Phenix input data deck has evolved through an extensive search of the available literature. The numbers have been uncovered in bits and pieces from a wide spectrum of references, with cross-checking to minimize the chance of large discrepancies. Where direct numbers were unavailable, they were generally estimated from related information, or else assumed. In case of unknown dimensions, they were estimated from a diagram believed to be drawn to scale 20 .

A sample input data deck for Phenix will be presented in the Users' Manual for SSC-P, to be issued subsequently to this report. However, it was felt it would be useful to devote a small section to discuss the ways in which some of the data, not available in the literature, were obtained.

\subsection{CORE DATA}

\subsubsection{Flow Fractions}

The average flow per fuel assembly is $22.7 \mathrm{~kg} / \mathrm{s}^{21}$. Thus, the flow through 103 fuel assemblies is $2338 \mathrm{~kg} / \mathrm{s}$. With the total core flow at rated power being $2760 \mathrm{~kg} / \mathrm{s}$, the flow fraction in the fuel channel is calculated to be 
0.845 . This leaves 0.155 for the blanket channel. Here, the flow through the control and shielding assemblies is assumed to be lumped with the blanket channel.

\subsubsection{Power Fractions}

From the natural circulation results for CRBRP using SSC $-L^{23}$, it is seen that, at $t=400$ seconds following scram, the ratio

$$
\frac{\text { normal ized power in blanket }}{\text { normalized power in fuel }}=1.4839
$$

Under full power conditions $(t=0 \mathrm{sec})$, this ratio is 1.0 . Also, at $t=400$ sec., the power generation is due exclusively to decay power. Therefore, we can write

$$
\frac{P_{b d}}{P_{b o}} / \frac{P_{f d}}{P_{f o}}=.1 .4839
$$

or

$$
\frac{P_{\text {bo }}}{P_{f o}}=0.6739 \frac{P_{b d}}{P_{f d}}
$$

where $P_{f d}$, $P_{b d}$ are the decay power in fuel and blanket assemblies, respectively, and $P_{f o}$, $P_{b o}$ are the respective powers corresponding to fullpower conditions.

We assume that Eq. (5-3) also applies to the Phenix reactor. During refueling operations in Phenix ${ }^{22}$, 17 fuel assemblies give out $40 \mathrm{KW}$ of decay heat, and 11 blanket assemblies give out $7 \mathrm{~kW}$ of decay heat (assuming power due to control assemblies is lumped in with the blankets). Using this information and taking $P_{f d}$, $P_{b d}$ as power per respective assembly, we derive the ratio of full power conditions per assembly as

$$
\frac{P_{\text {bo }}}{P_{\text {fo }}}=0.182
$$


There are 90 radial blanket assemblies and 103 fuel assemblies in the Phenix core, producing nearly $563 \mathrm{MW}$ of power. We can write this as

$$
90 \mathrm{P}_{\text {bo }}+103 \mathrm{P}_{\text {fo }}=563 \mathrm{MW}
$$

Combining Eqs. (5-4), (5-5) gives $P_{f_{0}}=4.728 \mathrm{MW}$ and $P_{b o}=0.8445 \mathrm{MW}$. Thus, the power fractions in fuel and radial blanket regions are calculated to be 0.865 and 0.135 , respectively.

\subsubsection{Fuel Hot Channel}

The radial peaking factor for Phenix is $1.3^{24}$. Using this, we obtain the power generated in the fuel hot channel as 6.1464 MW. Assuming the hot channel to represent only one assembly, the power fraction in the hot channel is calculated to be 0.01092 . This leaves 0.85408 for the remaining 102 fuel assemblies.

From the analytical results of Freslon, et. al..$^{5}$, we obtain the steadystate temperature rise in the nominal fuel hot channel ( $\Delta T_{f h c}$ ) as $235.24 K$. Energy balance for the coolant in the channel can be written as

$$
W_{\text {fhc }} C \Delta T_{f h c}=P_{f h c}
$$

where $C$ is the average heat capacity of the coolant in the hot channel. With $P_{\text {fhc }}$ and $\Delta T_{\text {fhc }}$ known, Eq. (5-6) can be used to determine the flow $W_{f h c}$, and hence the flow fraction $W_{f h c}$. Note that since $C$ is the integrated average over thc channel, and heice nut readlly obtainable by hand calculations, the desired flow fraction was obtained after a few computer trials. Table I presents the power and flow fractions in the fuel hot channel (Ch. 1), average fuel channel (Ch. 2), and blanket channel (Ch. 3). The coolant temperature 
rise values in the last column were obtained from a steady-state run using SSC-P.

Table I

Steady-state Power and Flow Fractions

\begin{tabular}{|c|c|c|c|c|}
\hline $\begin{array}{c}\text { Channel } \\
\text { No. }\end{array}$ & $\begin{array}{c}\text { Number } \\
\text { of } \\
\text { Assemblies }\end{array}$ & $\begin{array}{c}\text { Power } \\
\text { Fraction }\end{array}$ & $\begin{array}{c}\text { Flow } \\
\text { Fraction }\end{array}$ & $\begin{array}{c}\text { Coolant } \\
\text { Temp. Rise, } k\end{array}$ \\
\hline 1 & 1 & 0.01092 & 0.007365 & 235.32 \\
2 & 102 & 0.85408 & 0.837635 & 161.43 \\
3 & 90 & 0.135 & 0.155 & 137.76 \\
\hline
\end{tabular}

\subsubsection{Axial Power Profile in Fuel}

Heat flux on fuel element surface ${ }^{21}=143 \mathrm{~W} / \mathrm{cm} \quad$ (av.)

$=208 \mathrm{~W} / \mathrm{cm} \quad(\max$.

This can be used to evaluated the ratio of maximum to average power fraction in the fuel element as

$$
\frac{q_{\max }}{\bar{q}}=1.4545
$$

A parabolic profile of local power fraction $q^{\prime}$ can be constructed as

$$
q^{\prime}=\frac{q}{\bar{q}}=A_{z}^{2}+B z+c
$$

where $A, B, C$ are constants and $z$ is the axial distance along the fuel element of length $L$. 
Boundary conditions on Eq. (5-8) are

(i) $\quad q^{\prime}=0 \quad$ at $z=0$

(ii) $q^{\prime}=0 \quad$ at $z=L$

(iii) $q^{\prime}=1.4545$ at $z=L / 2$

Applying (i), ( $i i)$, ( $i i i)$ to Eq. (5-8), with $L=0.85 \mathrm{~m}$, the profile is obtained as

$$
q^{\prime}=-8.053 z^{2}+6.845 z
$$

The active fuel region within the fuel pin is divided into equidistant nodes. Therefore, we can construct a table of F5PAX (i.e. $q^{\prime}$ ) corresponding to midpoints in each nodal volume as shown below.

\begin{tabular}{r|r} 
N & F5PAX \\
\hline 1 & 0.2764 \\
2 & 0.7418 \\
3 & 1.0909 \\
4 & 1.3236 \\
5 & 1.4400 \\
6 & 1.4400 \\
7 & 1.3236 \\
8 & 1.0909 \\
9 & 0.7418 \\
10 & 0.2764
\end{tabular}

These can be read in for the 10 axial nodes of the fuel region. Axial blanket, etc., do not have significant contributions, and have been left as before. 


\subsection{PRIMARY SYSTEM}

\subsubsection{Pump Parameters}

The rated motor torque was extimated from information on the rated speed $N_{R}(r p m)$ and power consumption $P(W)$ of the motor at that speed. The formula is

$$
\tau_{m R}=\frac{60 P}{2 \pi N_{R}}(N-m)
$$

From this, the rated torque, ${ }^{\tau} R$, (the hydraulic torque at rated speed) is obtained from

$$
{ }^{\tau} R={ }^{\tau} m R-\tau_{f, R}
$$

where $\tau_{f, R}$ is assumed to be a known, small fraction of ${ }^{\tau} R$. The pump inertia, $I_{p}$, has been evaluated with the aid of a few trial-and-error runs to achieve the time required to reach half-speed, $\tau 1 / 2$, of $7.5 \mathrm{sec}$. as reported in the literature 25 . With each run, the next guess is obtained using the approximated relation

$$
\frac{I_{P}}{I_{p}^{1}}=\frac{\tau_{\frac{1}{2}}}{\tau_{\frac{1 / 2}{2}}^{1}}
$$

About two or three guesses were sufficient.

It is also known that the pump reaches approximately $10 \%$ speed in 60 seconds ${ }^{26}$. This information was used to revise the coefficients in the frictional torque correlation ${ }^{13}$

$$
\tau_{f r}=\tau_{R}\left(c_{0}+c_{1} \alpha\right)
$$

The first guess was obtained assuming a linear coastdown between 20 and 60 seconds, and using a test run to obtain the values of $\Omega$ at 20 and 40 seconds. 
Then, the pump speed equation can be written as

$$
\begin{aligned}
\frac{2 \pi I}{60} \frac{\left(\Omega_{60}-\Omega_{20}\right)}{40} & =-\tau_{R}\left[C_{0}+C_{1} \alpha+0.44652 \alpha^{2}\right. \\
& +0.5065 \alpha^{2}\left(\frac{\nu}{\alpha}\right)+0.59643 \alpha^{2}\left(\frac{v}{\alpha}\right)^{2} \\
& -0.64055 \alpha^{2}\left(\frac{\nu}{\alpha}\right)^{3}-0.025531 \alpha^{2}\left(\frac{v}{\alpha}\right)^{4} \\
& \left.+0.11531 \alpha^{2}\left(\frac{v}{\alpha}\right)^{5}\right]
\end{aligned}
$$

With $\alpha$ evaluated at $t=40 \mathrm{sec}$ as the linear average between $\alpha_{60}$ and $\alpha_{20}$, Eq. (5-14) simplifies to

$$
c_{0}+0.045 c_{1}=0.0056631 \text {. }
$$

Further, from rated conditions, we have that

$$
c_{0}+c_{1}=0.035
$$

Eqs. (5-15), (5-16), solved simultaneously, yield

$$
c_{0}=0.001, c_{1}=0.034 \text { for } 0.017<\alpha \leq 1.0
$$

To assure continuity, $c_{0}, c_{1}$ are redefined for the other 2 regions as

$$
\begin{array}{ll}
c_{0}=0.117, c_{1}=-9.458 & \text { for } 0.005<\alpha \leq 0.0117 \\
c_{0}=0.005, c_{1}=12.942 & \text { for } 0 \leq \alpha \leq 0.005
\end{array}
$$

\subsubsection{Data on Structures}

The mass heat capacities of structures are needed for transient energy balance calculations. Since the thermal barrier (metal $\mathrm{m} 2$ ) is a curibination of structure and sodium (or some other medium), it was decided to input (MC) $\mathrm{m2}$ rather than $M_{m 2}$ alone. The same was also done for metals $\mathrm{ml}, \mathrm{m} 3$ and $\mathrm{m} 4$.

Specific heat of structure is given by ${ }^{9}$

$$
\begin{aligned}
C(T)=380.962+0.535104 T & -6.01413 \times 10^{-4} \mathrm{~T}^{2}\left(5-10^{-7} \mathrm{~T}^{3}\right. \\
& +3.02469 \times 10^{-3}
\end{aligned}
$$


and for sodium, by

$$
C(T)=1630.22-0.83354 T+4.62838 \times 10^{-4} T^{2}
$$

The heat capacities are then evaluated at expected operating temperatures for $\mathrm{ml}, \mathrm{m} 2,, \mathrm{~m} 3, \mathrm{~m} 4$.

Metal $\mathrm{m} 2$,

$$
\begin{aligned}
& M_{s t r}=A_{h m 2} N_{p} \delta_{p} \rho_{s t r} \\
& M_{\mathrm{Na}}=A_{h m 2}\left(N_{p}-1\right) \delta_{\mathrm{Na}} \rho \mathrm{Na}
\end{aligned}
$$

The density of the metal is assumed to be $7750 \mathrm{~kg} / \mathrm{m}^{3}$.

Then

$$
(M C)_{m 2}=(M C)_{s t r}+(M C)_{N a}
$$

Due to lack of available data on upper internal structures, $(M C)_{m 1}$ is assumed to be the same as the value for CRBRP. Note that the part of IHX and pump wells in hot pool sodium can, on user choice, be lumped together with metal $\mathrm{ml}$.

Metal m3

The mass of metal $\mathrm{m} 3$ is

$$
M_{m 3}=M_{\text {roof }}+\text { mass of tank wall exposed to cover gas. }
$$

The area of contact between cover gas and $\mathrm{m} 3$ is

$$
A_{g m 3}=A_{h g}+A_{c g}+\pi D_{\text {tank }}\left(Z_{\text {tank }}-Z_{C P}\right)
$$

Metal $\mathrm{m} 4$

Mm4 was obtained as the sum of the mass of tank wall exposed to cold pool temperature $\left(M_{\text {wal }} 1\right)$ and the mass of core support structure. Further, it was assumed that $70 \%$ of the core support platform is solid steel, and that the mass of the support cone is negligible in comparison.

The heat transfer coefficients between sodium and the structures were assumed constant. 
In computing heat transfer area, the area of the support platform was assumed negligible. The area of support cone is

$$
A_{\text {cone }}=\frac{\pi}{4 \cos \theta}\left(D_{0}^{2}-D_{j}^{2}\right)
$$

where $\theta$ is the angle the cone makes with the horizontal.

Finally,

$$
A_{c m} 4=A_{\text {cone }}+A_{\text {wall }}
$$




\section{CODE DESCRIPTION}

\subsection{CODE DEVELOPMENT APPROACH}

SSC was conceived as a series of advanced computer codes to analyze the transient behavior for a variety of LMFBR plant designs. In order to easily accommodate all the models and integration methods needed for such a diversified analysis, and to allow for maximum flexibility in the system to be analyzed, the parent code, SSC-L, was designed to be a highly modular and variably dimensioned code. SSC-L can only be applied to study loop-type LMFBRs. However, by exploiting the highly modular structure and flexibility of SSC-L, another version of SSC, to analyze pool-type LMFBRs, could be readily developed. A complete and new code was therefore not necessary for SSC-P since only the modules and submodules necessary to describe the characteristics specific to the pool design needed to be changed or added. The remainder of the code was obtained from the existing and tested SSC-L library.

Code development using this approach, however, was not without its pitfalls since SSC-L was undergoing continual upgrading and modifications. The most serious question was how to continue the $P$-development around a given L-cycle and yet keep pace with the latest cycle generated. While there was no unique and simple solution, the method chosen would have to reflect the minimum effort required to achieve the desired objective. The method adopted was to consolidate all the pool modules, common blocks and data blocks into a separate program library. In this context, a 'pool module' is any routine used in the pool version that differs in any fashion from the corresponding routine in 
the loop version. In this way, the routines common to both versions, but unaffected by the pool version are kept exclusively in the SSC-L program library, and stay current with its development without any extra effort. Two program libraries describe the current state of the SSC-P code. They are the current 'official' cycle of SSC-L and the most current cycle of SSC-P. The program library 'SSC-P' consists mainly of the following submodules:

-- Primary heat transport system input, output, restart.

-- Steady-state and transient core plena

-- Steady-state and transient pool hydraulics, and energy balance in the primary tank.

In addition, several other subroutines are also included which were affected due, in some instances, to a different nomenclature (e.g., flow rates, pressure losses, levels, etc. in the primary system), and sometimes to a different model employed.

In creating the SSC-P library, all programming features of SSC-L were preserved, namely:

-- adherence to ANSI - standards

-- naming convention that uniquely identifies modules and variables in the code

-- highly modular structure

-- variablc dimensiuning scheme

The code development approach described above, while strictly following the philosophy of SSC-L, allows for easy maintenance of pool-related subroutines, without concern and duplication of effort in the upgrading of the remaining parts of the code. In addition, less than one third of the space that 
would be required by a single, completely independent SSC-P library is needed to store the code in either a permanent file, tape or disk, and in case of any change made to the program, the compilation time is considerably less within the facilities of a computer such as the CDC-7600.

\subsection{FLOWCHARTS AND SUBROUTINE DESCRIPTIONS}

Flow charts for the main drivers, along with their modules and submodules, are shown in Figs. 23-26. New and modified subroutines are presented in the logical order of their calls within the global SSC code. All submodules that are exclusive to the SSC-L program library ${ }^{27}$, have been omitted. A short description of the subroutines in SSC-P is given below. Many of the drivers, modules and submodules modified from SSC-L and which form a part of the SSC-P library have been omitted because their basic function, hence definition, has not changed from SSC-L. These definitions can be found in the documentation on SSC-L. 9

$\underline{\text { LOOP } 1 \mathrm{U}}$

This subroutine sums up the elevation differences of both primary and intermediate systems, based on user-iniput gcometric prnfile data, and checks for convergence against a user-specified criterion. This ensures a cunsistent profile specification before the code goes into detailed system computation. POOLIU

This subroutine displays, on request, all the pool common blocks along with their contents, during transient. PSAV9U

this subroutine writes all pool common blocks on a restart file, during either steady-state or transient. 
This subroutine reads all pool common blocks from a restart file. $\underline{\text { DRIVIS }}$

This subroutine is the driver for the solution of energy balance in the pools during steady-state. Starting from an initial guess for cold pool temperature $\left(T_{C P}\right)$; it iterates between HTPLIS and CDPLIS until a converged value of $T_{C P}$ is obtained.

HPTL1S

This subroutine performs energy balance in the hot pool and iterates to calculate the steady-state temperatures in the hot center pool, barrier, cover gas and structures for a given value of cold pool temperature. CDPL1S

This subroutine, iterates to converge on a new value for cold pool temperature, based on barrier and cover gas temperatures determined from HTPLIS. It also determines primary pump inlet and outlet enthalpies. $\underline{\text { UBRRIU }}$

This is a subroutine, currently called by HTPLIS; that computes overall heat transfer coefficients $\left(U_{\mathrm{hm} 2}, U_{\mathrm{cm} 2}\right)$ for the thermal barrier. HBRRIU

This function computes the film heat transfer coefficient from barrier to either hot. nr cold pool, as parl of the computations for overall heat transfer coefficient in UBRRIU.

\section{BPASIS}

This subroutine, called from PBAL9S, computes steady-state pool external bypass flow rate and inlet and outlet pressures. 
RITEIS

This subroutine prints primary pool system steady-state information. POOLIS

This subroutine drives the steady-state hydraulic calculations for the primary system. In addition to interpreting logical variables to arrange the calling sequence to appropriate component submodules, it also evaluates pressure drops in the regions of hot and cold pool lying between the reactor and IHXs. Both hot pool and cold pool design options are covered. In case of the cold pool option, both thermal and hydraulic calculations would be included.

\section{LEVLIS}

For the hot pool concept, this subroutine computes the steady-state level in the cold pool, with hot pool level assumed user input. It also computes the volume and mass of the cover gas blanket above the free surfaces. RES2S

This subroutine computes the coolant level in a spherical pump given the volume of coolant in it, and sets the inlet pressure to the intermediate sodium pump. The mass of cover gas above the coolant level is also calculated. TANK2S

This subroutine computes the level of coolant in the buffer (surge) tank, given the pressure of cover gas from input and the pressure at the tank location from PRES2S. It also calculates the mass of cover gas in the tank. POOLIT

This subroutine is the driver for transient thermal balance in the pools. ZONEIT

This subroutine computes the penetration of core flow, the volumes of the two zones in the hot pool heat transfer area for each zone and the barrier 
heat transfer coefficients. It also updates the sodium volume in the hot and cold pools during the transient.

HTPLIT

This subroutine computes the time derivatives of enthalpy (or temperature) in the hot pool, cold pool, cover gas, barrier, and all other structures. 


\section{REFERENCES}

1. M. E. Durham, "Optimization of Reactor Design for Natural Circulation Decay Heat Removal in a Pool-Type LMFBR", Optimization of Sodium - Cooled Fast Reactors, British Nucl. Energy Soc., London (1977).

2. D. Mohr and E. E. Feldman, "A Dynamic Simulation of the EBR-II Plant During Natural Convection with the NATDEMO Code", Proceedings of the Specialists Meeting on Decay Heat Removal and Natural Convection in FBR's, Upton, NY, February, 1980 (to be published).

3. "Pool-Type LMFBR Plant, 1000 MWe Phase A Design", EPRI NP-646, Vol 1, Part II, Electric Power Research Institute (1978).

4. D. Mohr, "NATCON, A Dynamic Code for Evaluating the Thermal-Hydraulic Behavior of the EBR-II Primary System, Including the Effect of Natural Convection", Reactor Develoment Progress Report, ANL-RDP-74, P. 1.11 (August 1978).

5. "LMFBR Demonstration Plant Simulation Model, DEMO", Westinghouse Advanced Reactors Division, WARD-D-0005, Rev. 4 (1976).

6. M. Khatib-Rahbar, "System Modeling for Transient Analysis of Loop-Type Liquid-Metal-Cooled Fast Breeder Reactors", Cornell University Nuclear Reactor Laboratory, CURL-53 (1978).

7. J. R. Raber, "System Modeling for a Pool-Type Liquid Metal-Cooled Fast Breeder Reactor" "Cornell University Nuclear Reactor Laboratory, CURL-56 (1980).

8. I. K. Madni and A. K. Agrawal, "A Work Plan for the Development of SSC-P", Brookhaven National Laboratory, BNL-NUREG-24225 (1978).

9. A. K. Agrawal, et al., "An Advanced Thermohydraul ic Simulation Code for Transients in LMFBR̉s (SSL-L Cude)", Brookhaven National Laboratory, BNL-NUREG-50773 (1978).

10. E. R. G. Eckert and R. Drake, Jr., "Analysis of Heat and Mass Transfer", McGraw-Hill, Inc. (1972).

11. B. Gebhart, "Heat Transfer", McGraw-Hill, Inc., 2nd. Edition (1971).

12. I. K. Madni and E. G. Cazzoli, "A Single-Phase Pump Model for Analysis of LMFBR Heat Transport Systems", Brookhaven National Laboratory, BNL-NUREG-50859 (1978).

13. I. K. Madni, E. G. Cazzoli and A. K. Agrawal, "A Single-Phase Sodium Pump Model for LMFBR Thermal-Hydraulic Analysis", Proceedings of the International Meeting on Fast Reactor Safety Technology, Seattle, Washington, August 19-23, 1979. 
14. V. Quan and A. K. Agrawal, "A Pipe-Break Model for LMFBR Safety Analysis", Brookhaven National Laboratory BNL-NUREG-50688 (1977).

15. R. S. Burington, Handbook of Mathematical Tables and Formulas, 4th Edition, McGraw-Hi11, 1965.

16. J. W. Yang, "An Analysis of Transient Thermal Response in the Outlet Penun of an LMFBR", Brookhaven National Laboratory, BNL-NUREG-50521 (1976).

17. J. W. Yang, "Penetration of Core Flow in Upper Plenum of an LMFBR", Trans, Am. Nuc1. Soc. 23, 414 (1976).

18. I. K. Madni, "Transient Analys is of Coolant Flow and Heat Transfer in LMFBR Piping Systems", Brookhaven National Laboratory, BNL-NUREG-51179 (1980).

19. F. T. Krogl, "Variable Order Integrators for the Numerical Solution of Ordinary Differential Equations", Jet Propulsion Laboratory Report, May $1,1969$.

20. A. Amorosi, et al., "An Overview of Pool-Type LMFBRs, General Characteristics", Argonne National Laboratory, ANL-76-71 (1976).

21. "PHENIX" in Directory of Nuclear Reactors, Vol. IX, Power Reactors, IAEA (1971).

22. A. K. Agrawa1, et al., "Dynamic Simulation of LMFBR PLant Under Natural Circulation", ASME Paper No. 79-HT-6, 1979.

23. Phenix, Prototype Fast-Neutron Nuclear Power Station, Bulletin d'Information Scientifiques et Techniques No. 138 (June 1969); AEC-tr-7130 (Feburary 1970).

24. W. B. Wolfe, Monthly Report No. 11, Atomics International, Nov. 1973.

25. H. Freslon, et al., "Analysis of the Dynamic Behavior of the Phenix and Super Phenix Reactors during certain Accident Sequences", Proc. Int. Mtg. on Fast Reactor Safety Technology, Vol. II I, Seattle, Wash., Aug. 19-23, 1979.

26. E. R. Appleby, "Compilation of Data and Descriptions fur U.S. and Foreign Liquid Metal Fast Breeder Reactors", Hanford Engineering Develupment Laboratory, HEDL-TME-75-12 (Aug. 1975).

27. A. K. Agrawal, et al., "Users' Manual for the SSC-L Code", Brookhaven National Laboratory BNL-NUREG-50914 (1978). 
RECEIVED BY TIC JAN 14 I98I

3
4
5

$\therefore \quad 3$

. 9 